UNIVERSIDADE DE SÃO PAULO

FACULDADE DE ODONTOLOGIA

\title{
INFLUÊNCIA DO ESTADO DIABÉTICO SOBRE A ATIVIDADE E DISTRIBUIÇÃO DAS ENZIMAS HEXOQUINASE E FOSFOFRUTOQUINASE-1 NAS GLÂNDULAS SUBMANDIBULAR E PARÓTIDA DE RATOS
}

\section{FERNANDO NEVES NOGUEIRA}

Dissertação apresentada à Faculdade de Odontologia da Universidade de São Paulo, para obter o Título de Mestre, pelo Programa de Pós-Graduação em Odontologia.

Área de Concentração: Materiais Dentários Orientador: Prof. Dr. José Nicolau

São Paulo 


\section{ERRATA}

Página 48, linha 10

Onde se lê: ... solúvel sujeita e não a regulação ...

Leia-se: ... solúvel e na fração ligada a regulação...

Página 48, linha 14

Onde se lê: ... na fração solúvel, a PFK-1 não estaria sujeita a nenhuma...

Leia-se: ... na fração solúvel e ligada, a PFK-1 estaria sujeita a alguma...

Página 50, linha 16

Onde se lê: ... solúvel, em condições sujeita ou não ao controle ... Leia-se: ... solúvel e ligada, em condições sujeita ao controle... 
Data da Defesa:

1

\section{Banca Examinadora}

Prof. Dr.

Julgamento:

Assinatura:

Prof. Dr.

Julgamento:

Assinatura:

Prof. Dr.

Julgamento:

Assinatura: 


\section{Catalogação-na-Publicação}

Serviço de Documentação Odontológica

Faculdade de Odontologia da Universidade de São Paulo

Nogueira, Fernando Neves

Influência do estado diabético sobre a atividade e distribuição das enzimas hexoquinase e fosfofrutoquinase-1 nas glândulas submandibular e parótida de ratos / Fernando Neves Nogueira ; orientador José Nicolau. -- São Paulo, 2001.

64f. : fig.

Dissertação (Mestrado - Programa Pós-Graduação em Odontologia. Área de Concentração: Materiais Dentários). -- Faculdade de Odontologia da Universidade de São Paulo.

1. Enzimas - Glândulas submandibulares - Diabéticos

2. Enzimas - Glândula parótida-Diabéticos 3. Materiais dentários.

CDD 617.695

BLACK D16 
Dedico este trabalho

Aos meus pais, Roberto e Maria Helena, meu eterno agradecimento pois, se hoje obtenho esse resultado, é uma conseqüência direta de tudo que recebi de vocês.

Aos meus irmãos, Flávia, Maurício e Cristina, os quais, infelizmente, nestes últimos anos, não pude compartilhar o convívio com vocês, saibam este trabalho é o resultado de uma realização pessoal.

A minha namorada, Fátima, de quem tive sempre o amor e compreensão, além de poder encontrar, nos seus braços, o carinho que precisei.

A vocês, meu amor e gratidão. 


\section{AGRADECIMENTOS}

Ao meu orientador, Prof. Dr. José Nicolau.

Seu esforço e dedicação foram alguns dos maiores presentes que essa vida me trouxe. Que essa paixão que você carrega continue contagiando nossas vidas pois somente quem teve o prazer de trabalhar com você, consegue imaginar o que é isso.

Ao meu amigo Douglas.

Onde atrás do sorriso, sempre pude contar sua sabedoria (e olha que com muita freqüência!). Saiba que este trabalho foi conseqüência também de sua ajuda.

A Profa. Rosa Helena.

Que em um certo dia foi atrás de um aluno da graduação que estivesse interessado em fazer um estágio com um professor da Bioquímica. Cinco anos depois aqui está o resultado! Saiba que você é uma das responsáveis por esta vitória. 
Aos amigos de Laboratório, Emily, Fausto, Mariana, Marisa, Monique e Walter.

Pela amizade, alegria e aprendizado.

Aos amigos do Departamento, Alessandro, Alessandra, André, Daniel, Ivo, José Roberto, Josete, Laiza, Marcela, Marcelo, Marcos, Milton, Paulo César, Sílvia, Waldyr, Antônio, Rosa Cristina, Prof. Leonardo, Prof. Rafael e Prof. Braga.

Pelos excelentes momentos de convivência.

À memória do Prof. Joel Biancchi, pelo exemplo de garra, determinação e vida.

À FAPESP, por ter financiado minhas pesquisas durante estes anos. (Processo 99/03768-8) 


\section{SUMÁRIO}

p.

LISTA DE FIGURAS

LISTA DE TABELAS

LISTA DE ABREVIATURAS E SIGLAS

LISTA DE SÍMBOLOS

RESUMO

1. INTRODUÇÃO

2. REVISÃO DA LITERATURA

2.1. METABOLISMO DE CARBOIDRATOS NAS GLÂNDULAS

SALIVARES

2.2. INFLUÊNCIA DO DIABETES SOBRE AS GLÂNDULAS SALIVARES

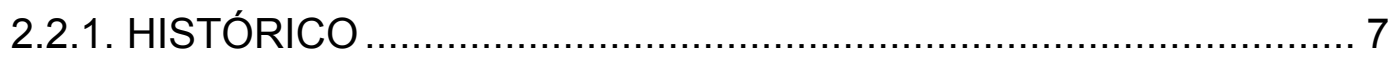

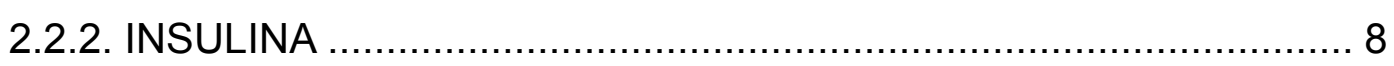

2.2.3. DIABETES E A GLÂNDULA PARÓTIDA ................................. 11

2.2.4. DIABETES E A GLÂNDULA SUBMANDIBULAR ...................... 12

2.2.5. DIABETES E A SECREÇÃO SALIVAR ................................. 13

2.3. METABOLISMO DE CARBOIDRATOS NO DIABETES ................. 15

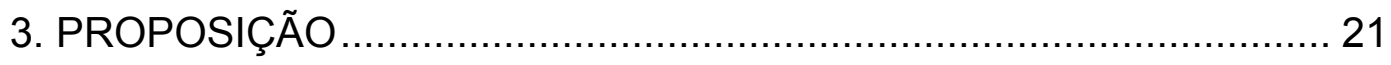

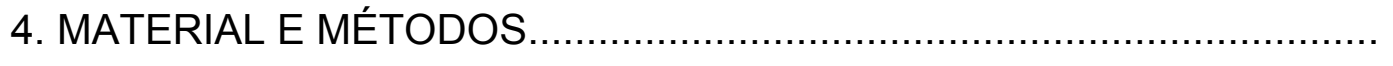

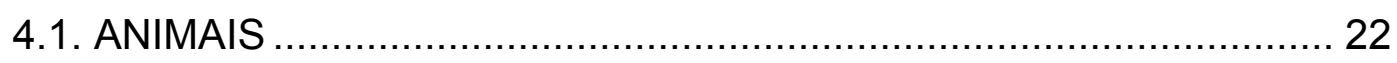

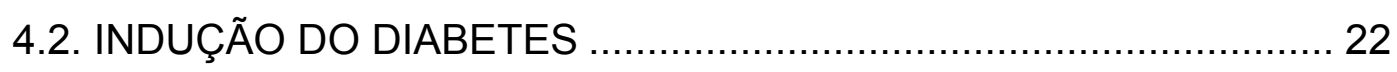

4.3. OBTENÇÃO DOS ANIMAIS ................................................. 22

4.4. ANÁLISES

4.4.1. DETERMINAÇÃO DA GLICEMIA DOS ANIMAIS ....................... 23

4.4.2. DETERMINAÇÃO DA HK PARTICULADA E SOLÚVEL ............... 23 
4.4.3. DETERMINAÇÃO DA PFK-1 SOLÚVEL E LIGADA AO

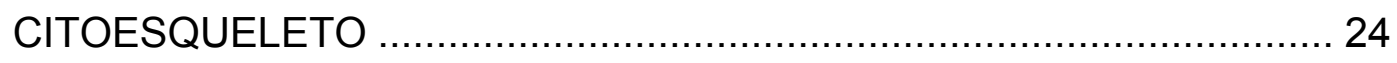

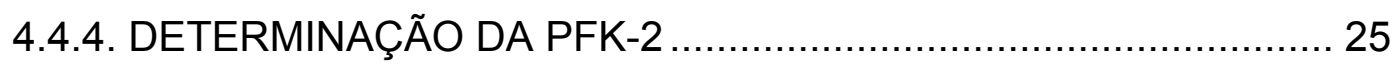

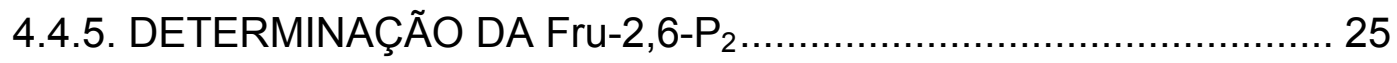

4.4.6. DETERMINAÇÃO DE ISOENZIMAS DE HK .............................. 26

4.4.7. DETERMINAÇÃO DE PROTEÍNA TOTAL ................................ 27

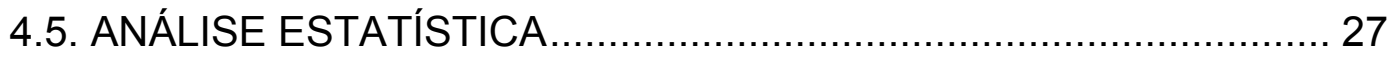

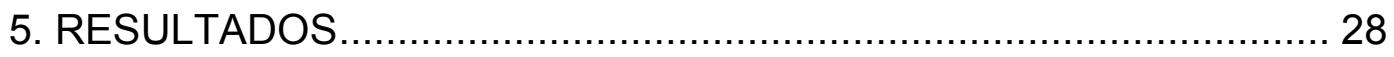

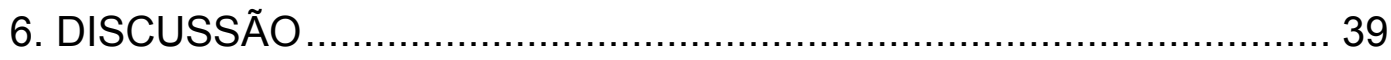

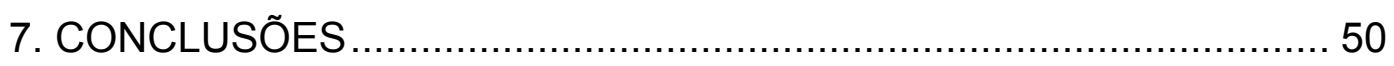

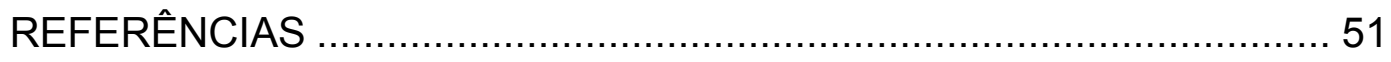

SUMMARY 


\section{LISTA DE FIGURAS}

Figura 5.1 - Perfil cromatográfico da HK solúvel de glândula submandibular (controle e diabético), após passagem em coluna de DEAE-Celulose ( 1 x 4 $\mathrm{cm})$ e eluída em gradiente linear de $\mathrm{KCl}(0-0,5 \mathrm{M})$ em tampão fosfato, e coletado em frações de $3 \mathrm{ml}$.

Figura 5.2 - Perfil cromatográfico da HK ligada de glândula submandibular (controle e diabético), após passagem em coluna de DEAE-Celulose (1x4 $\mathrm{cm})$ e eluída em gradiente linear de $\mathrm{KCl}(0-0,5 \mathrm{M})$ em tampão fosfato, e coletado em frações de $3 \mathrm{ml}$. 36

Figura 5.3 - Perfil cromatográfico da HK solúvel de glândula parótida (controle e diabético), após passagem em coluna de DEAE-Celulose (1x4 $\mathrm{cm})$ e eluída em gradiente linear de $\mathrm{KCl}(0-0,5 \mathrm{M})$ em tampão fosfato, e coletado em frações de $3 \mathrm{ml}$.

Figura 5.4 - Perfil cromatográfico da HK ligada de glândula parótida (controle e diabético), após passagem em coluna de DEAE-Celulose (1 $1 \times 4$ $\mathrm{cm})$ e eluída em gradiente linear de $\mathrm{KCl}(0-0,5 \mathrm{M})$ em tampão fosfato, e coletado em frações de $3 \mathrm{ml}$ 


\section{LISTA DE TABELAS}

Tabela 5.1 - Glicemia, pesos corpóreo, glandular e relativo (PGR) de ratos diabéticos sacrificados 30 dias após a indução e controle 31

Tabela 5.2 - Atividade específica da HK, expressa em $\mathrm{mU} / \mathrm{mg}$ de proteína, nos estados solúvel e ligado a mitocôndria, em glândulas submandibular e parótida de ratos diabéticos induzida por estreptozotocin, e de controles, sacrificados 30 dias após a indução do diabetes. 32

Tabela 5.3 - Distribuição da PFK-1, expressa em $\mathrm{mU} / \mathrm{mg}$ de proteína, entre as frações solúvel e ligada ao citoesqueleto, no pH 6,9 (sujeito a regulação alostérica) e no pH 8,2 (não sujeito a regulação alostérica), em glândulas submandibular e parótida de ratos diabéticos induzida por estreptozotocin, e de controles, sacrificados 30 dias após a indução do diabetes. 33

Tabela 5.4 - Atividade específica da PFK-2 e conteúdo de Fru-2,6- $\mathrm{P}_{2}$ em glândulas submandibulares de ratos diabéticos induzida por estreptozotocin, e de controles, sacrificados 30 dias após a indução do diabetes. 


\section{LISTA DE ABREVIATURAS E SIGLAS}

ADP - Adenosina-bisfosfato

AMP - Adenosina-monofosfato

ATP - Adenosina-trifosfato

DTT - Ditiotreitol

EDTA - Ácido etilenodiaminotetracetico

Fru-1,6-P 2 - Frutose-1,6-bisfosfato

Fru-2,6- $\mathrm{P}_{2}-$ Frutose-2,6-bisfosfato

Fru-2,6- $\mathrm{P}_{2}$ ase- Frutose-2,6-bisfosfatase

Fru-6-F - Frutose-6-fosfato

G - Glicose

G-6-P - Glicose-6-fosfato

G-6-PD - Glicose-6-fosfato desidrogenase

GLPA - Glândula Parótida

GLSL - Glândula Sublingual

GLSM - Glândula Sub-Mandibular

HK - Hexoquinase

$\mathrm{KCl}$ - Cloreto de potássio

Kg - Quilograma

LDH - Lactato-desidrogenase

mg - Miligrama

$\mathrm{MgCl}_{2}-$ Cloreto de magnésio

$\mathrm{NaF}$ - Fluoreto de sódio

$\mathrm{NaOH}$ - Hidróxido de sódio 
ns - Não Significante

PEP - Fosfoenolpiruvato

PFK-1 - Fosfofrutoquinase 1

PFK-2 - Fosfofrutoquinase 2

PIR - Piruvato

$\mathrm{pH}$ - Potencial hidrogeniônico

PMSF - Fenilmetilsulfonilfluoreto

$U$ - Unidade 


\section{LISTA DE SÍMBOLOS}

Mg - Magnésio

n - Tamanho da amostra 


\section{RESUMO}

\section{INFLUÊNCIA DO ESTADO DIABÉTICO SOBRE A ATIVIDADE E DISTRIBUIÇÃO DAS ENZIMAS HEXOQUINASE E FOSFOFRUTOQUINASE-1 NAS GLÂNDULAS SUBMANDIBULAR E PARÓTIDA DE RATOS}

$\mathrm{Na}$ presente investigação estudamos a possível influência da falta da insulina sobre a atividade de duas enzimas importantes para a via glicolítica: a hexoquinase (HK) e a fosfofrutoquinase-1 (PFK-1), nas glândulas submandibular (GLSM) e parótida (GLPA) de ratos. Para isso, em ratos mantidos em jejum durante aproximadamente 15 horas foi injetado, via intraperitonial, estreptozotocin dissolvido em tampão citrato $0,1 \mathrm{M}$ pH 4,5 (60 $\mathrm{mg} / \mathrm{Kg}$ de peso corporal). 48 horas após a indução, o sangue dos animais foi coletado e a glicemia determinada. Somente aqueles ratos que apresentaram glicemia igual ou acima de 350mg de glicose/100 ml de sangue foram utilizados. Os animais foram sacrificados 30 dias após a indução do estado diabético, por traumatismo craniano. As GLSM e GLPA foram removidas e analisadas para atividade e distribuição das enzimas HK e PFK-1. A enzima HK foi determinada no citosol (fração solúvel) e ligada a mitocôndria (fração ligada). A enzima PFK-1 foi determinada no citosol 
(fração solúvel) e ligada ao citoesqueleto (fração ligada) em dois pHs: pH 6,9 , sujeito a regulação alostérica e $\mathrm{pH} 8,2$, em que mostra atividade máxima. $\mathrm{Na}$ GLPA observamos aumento da atividade da HK tanto na fração solúvel (aproximadamente 33\%) quanto na fração ligada a mitocôndria (aproximadamente 85\%). Relativamente a isoenzimas de $\mathrm{HK}$, não verificamos alteração no estado diabético. A atividade da enzima PFK-1 na GLPA não apresentou alterações quer considerando a forma sujeita a regulação alostérica, quer a forma com atividade máxima e portanto, não sujeita a regulação. Na GLSM constatamos uma redução da enzima HK ligada a mitocôndria de aproximadamente $74 \%$, não havendo alteração da forma determinada no citosol (forma solúvel). Relativamente às formas isoenzimáticas, verificamos a perda de uma forma isoenzimática tanto na fração solúvel quanto na fração ligada. Por outro lado, observamos um aumento da atividade da PFK-1 da fração solúvel de aproximadamente $50 \%$ quando determinada em $\mathrm{pH}$ 6,9, que reflete a forma regulada alostericamente, e de aproximadamente $84 \%$ quando determinada em $\mathrm{pH}$ 8,2 e, portanto, não sujeito a regulação. Contrariando ao esperado, o conteúdo de Fru-2,6- $P_{2}$ nas GLSM de ratos diabéticos apresentou redução de aproximadamente $42 \%$ enquanto a atividade da PFK-2 também apresentou redução. 


\section{INTRODUÇÃO}

O diabetes melito é um termo que se refere a uma doença caracterizada por uma hiperglicemia crônica. Ela é classificada em dois tipos: Tipo I, também chamada de insulino-dependente (DMID), que acomete principalmente crianças e jovens que possuem algum distúrbio na produção de insulina; e Tipo II, que é também chamada de não-insulino-dependente (DMNID), que acomete principalmente adultos obesos, com idade superior a 35 anos que geralmente adquirem resistência ao hormônio insulina.

A insulina é um importante hormônio anabólico que desempenha um papel significante na regulação de inúmeras vias metabólicas, incluindo o metabolismo de carboidratos, armazenamento de glicogênio, síntese de ácido graxo, transporte de aminoácido e síntese de DNA, RNA e proteína.

Os principais sintomas apresentados pelos diabéticos são a polifagia (alta ingestão de alimento pois o organismo não é capaz de armazená-lo; sendo grande parte da glicose eliminada pela urina), a polidipsia (alta ingestão de água devido a pressão osmótica sanguínea positiva ocasionada pela alta concentração de glicose no sangue) e por fim a poliúria (por ingerir muita água, o diabético necessita urinar constantemente) (Little, 2000). 
Embora o processo secretório das glândulas parótida e submandibular, esteja primariamente, sob controle dos nervos simpático e parassimpático (Garrett et al., 1991), fatores dietéticos e hormonais influenciam as respostas ao estímulo farmacológico ou dos nervos diretamente (Anderson,1991).

A falta da insulina afeta o desenvolvimento das glândulas salivares (Liu \& Lin, 1969a), atividade da enzima amilase na glândula parótida (Anderson \& Johnson, 1981; Anderson, 1983; Szczepanski et al., 1998; Kim et al., 1990) e da enzima peroxidase na glândula submandibular (Anderson \& Shapiro, 1979). Entretanto, o tratamento crônico de ratos normais com doses diárias de insulina leva a hiperplasia e hipertrofia das GLSM e GLPA e aumento na incorporação de $\mathrm{H}^{3}$ Leucina pelas mesmas (Wang et al.,1994).

Quanto a saúde bucal, apesar de não haver um consenso, os principais sintomas apresentados pelos indivíduos diabéticos seriam um aumento na incidência de cárie e doença periodontal, aumento na incidência de candidose oral, alveolites pós-cirúrgicas e redução do fluxo salivar (Little, 2000).

Três teorias tentam explicar esta redução no fluxo salivar: A primeira sugere que a poliúria levaria a uma desidratação do organismo e esta desidratação seria a responsável pela redução do fluxo salivar. A segunda discute alterações na transdução de sinal celular, levando a uma menor resposta frente ao estímulo. A terceira aborda a falta da insulina levando a uma redução do metabolismo glandular e esta promoveria uma diminuição na quantidade de energia disponível à célula, reduzindo a secreção salivar. 
Entre as formas de regulação da atividade enzimática, podemos citar: (a) a distribuição entre formas solúvel e ligada; (b) a regulação alostérica, isto é, por metabólitos formados na própria célula; (c) ligação covalente, como é o caso de fosforilação e defosfrilação de algumas enzimas (Champe \& Harvey, 1994).

A insulina é um hormônio que tem influência sobre as enzimas Hexoquinase (HK) e Fosfofrutoquinase-1 (PFK-1) em quase todos os tecidos do organismo. As informações sobre a influência do estado diabético em enzimas do esquema glicolítico das glândulas salivares são poucas, razão que nos leva a examinar esse aspecto. 


\section{REVISÃO DA LITERATURA}

2.1.METABOLISMO DE CARBOIDRATOS NAS GLÂNDULAS SALIVARES

O funcionamento de células, tecidos e órgãos é dependente de energia. $O$ processo pelo qual as células obtêm essa energia consiste em uma série de reações integradas chamadas de metabolismo, sendo a glicose o principal substrato destas reações.

Estudos do metabolismo glandular estão associados a estudos da secreção glandular, sendo estes últimos associados ao consumo de glicose e oxigênio das glândulas (Deutsh \& Raper, 1936, 1938; Terroux et al.,1959; Stromblad, 1957, 1959; Pedroso et al., 1976; Nicolau \& Sassaki, 1976).

Os primeiros estudos com glândulas salivares submandibulares de cachorros, realizados por Anrep \& Cannan (1922, 1923), mostraram que a captação de glicose aumentava proporcionalmente à elevação do fluxo de secreção das glândulas.

Goldman et al. (1964) verificaram que em fatias de glândulas submandibulares (GLSM), ante condições aeróbicas e na presença de glicose, havia a formação de ácido lático. De 91 a $98 \%$ deste ácido era 
produzido a partir da glicose através da via glicolítica. Brock et al. (1967) sugeriam que, durante o repouso, o lactato poderia ser utilizado nas glândulas salivares para a síntese de glicogênio, pela gliconeogênese. Pedroso et al. (1976) mostraram, em fatias de glândulas submandibulares, diminuição na produção de ácido lático com aumento no tempo de incubação, sugerindo sua reutilização pela célula. Entretanto, a gliconeogênese em glândulas submandibulares foi descartada por Nicolau \& Sassaki (1976), mostrando que a atividade da enzima frutose-1,6bisfosfatase era muito baixa e não se alterava com o jejum. Além disso, esses autores mostraram baixíssima incorporação de $\mathrm{C}^{14}$ proveniente do ácido lático, marcado radioativamente, ao glicogênio.

English (1955) demonstrou a presença de glicose-6fosfatodesidrogenase em GLSM de ratos, sugerindo a funcionalidade da via das pentoses neste tecido. Por outro lado, Goldman et al. (1964) relataram que a quantidade de glicose utilizada na via das pentoses era muito pequena quando comparada com a utilização pela via glicolítica, concluindo que esta seria a principal via de oxidação da glicose.

A incubação de fatias de GLSM com glicose marcada com elemento radioativo por uma hora mostrou a incorporação do ${ }^{14} \mathrm{C}$ ao dióxido de carbono, lactato, malato, mucoproteínas e alguns aminoácidos, sendo que a adição de insulina ao meio aumentou a síntese de mucoproteínas (Masi et al., 1966). Além disso, esta mesma metodologia mostrou que a glicose pode ser utilizada na síntese de glicogênio e síntese de cadeias sacarídicas de glicoproteínas (Nicolau \& Sassaki, 1976). 
O metabolismo da glândula parótida (GLPA) pode ser classificado como predominantemente aeróbico (Feinstein \& Schramm, 1970; Nicolau \& Sassaki, 1976) e os da GLSM (Fernandes \& Junqueira, 1953; Nicolau \& Sassaki, 1976) e da glândula sublingual (GLSL) (Nicolau \& Sassaki, 1976) predominantemente anaeróbico.

Quando se estuda o metabolismo em glândulas salivares, o tipo glandular e a espécie de animal mostra grande importância. No estudo de Nicolau et al. (1974) foi mostrado que a atividade específica de algumas enzimas variavam entre as espécies e entre as glândulas dos animais, concluindo que não se deve generalizar os resultados obtidos em uma glândula para todas as três.

A HK é uma enzima que apresenta 4 isoenzimas distribuídas diferentemente no organismo (Katzen \& Schimke, 1965; Grossbard et al., 1966; Grossbard \& Shimke, 1966). A presença de isoenzimas de HK nas glândulas submandibular e parótida de ratos foi mostrada no estudo de Knull \& Lamb (1980), havendo predominância da isoenzima I, sendo também encontrada a isoenzima II. 


\subsection{INFLUÊNCIA DO DIABETES SOBRE AS GLÂNDULAS SALIVARES}

\subsubsection{HISTÓRICO}

O diabetes mellito é uma doença cujos relatos estão descritos desde a ano de 1500 ac, no antigo Egito. Os gregos, no século II dc, faziam referências a uma doença, a qual chamavam de diabetes, que era caracterizada como "uma estranha doença consistindo na carne e nos ossos fluindo juntos pela urina", levando o indivíduo à morte. No século VI, os indianos identificaram a substância doce da urina como sendo glicose, adicionando a palavra mellito ao diabetes (Notkins, 1979).

No final do século XIX, a causa do diabetes foi identificada por dois pesquisadores austríacos. Oscar Minkowski e Baron Joseph Von Mering (1889) identificaram no pâncreas a causa do diabetes, pois após sua remoção, cachorros normais apresentaram os sintomas da doença, iniciando, a partir desta data, os estudos do diabetes mellito.

No ano de 1921, os canadenses Frederick G. Banting e Charles $\mathrm{H}$. Best, mostraram que alguma substância do pâncreas seria a responsável pela prevenção do diabetes. Ao injetarem extrato de pâncreas em cachorros diabéticos, a glicemia dos animais foi reduzida. Desta forma foi possível iniciar o tratamento dos indivíduos que eram acometidos por esta enfermidade.

Na Odontologia, a pesquisa sobre a influência do diabetes nos tecidos orais foi iniciada somente em meados do século passado, quando Liu \& Lin 
(1969a) verificaram que em ratos, afetados pelo diabetes, ocorria um retardo no desenvolvimento corporal e glandular (tanto na GLSM quanto na GLPA). Como retardo entende-se um menor ganho de peso do animal ou do peso relativo da glândula e do diâmetro de seus ductos. Os animais em desenvolvimento, tratados com insulina durante o período do experimento, período este que não foi relatado, não apresentaram este retardo. Contudo, em animais adultos, foi observado também uma redução dos pesos glandulares e dos diâmetros dos ductos da GLSM. Este trabalho mostrou a importância da insulina no desenvolvimento e manutenção da função das glândulas salivares.

No mesmo ano, Liu \& Lin (1969b) confirmaram a importância da insulina no desenvolvimento tanto corporal quanto glandular em animais diabéticos ao mostrarem que somente com a administração de hormônio do crescimento $(\mathrm{GH})$ não foi possível a obtenção de valores normais de desenvolvimento, o que foi conseguido somente quando administrado este hormônio junto com insulina.

\subsubsection{INSULINA}

A insulina é um hormônio sintetizado pelas células beta do pâncreas como um precursor de cadeia única de 110 aminoácidos, chamado préproinsulina. Após translocação através da membrana do retículo plasmático, o peptídeo de sinalização constituído de 24 aminoácidos da extremidade Nterminal é rapidamente clivado para formar a proinsulina. A cadeia de

proinsulina se dobra e formam-se pontes dissulfeto. A proinsulina é então 
transferida para o aparelho de Golgi, onde sofre ação proteolítica, com remoção do peptídeo conector ou peptídeo $\mathrm{C}$, transformando-se em insulina. A molécula de insulina contém, portanto, duas cadeias polipeptídicas, a cadeia $\alpha$ constituída de 21 resíduos de aminoácidos enquanto a cadeia $\beta$ é constituída de 30 resíduos de aminoácidos.

A insulina é um importante hormônio anabólico, que desempenha papel significante na regulação de inúmeras vias metabólicas, incluindo o metabolismo de carboidratos, armazenamento de glicogênio, síntese de ácido graxo, transporte de aminoácido, síntese de DNA, RNA e proteína. O tratamento de insulina em células responsivas gera um sinal que regula os processos de transporte (glicose, aminoácidos e íons), ativa e inativa enzimas e regula a expressão gênica, a síntese de proteínas e de DNA (Rosen, 1987).

Após sua liberação pelas células beta do pâncreas, a insulina se liga ao seu receptor existente na membrana plasmática das células alvo. Os receptores de insulina são glicoproteínas transmembrânicas, heterotetraméricas, constituídos de duas subunidades alfa e duas subunidades beta. As subunidades são unidas por pontes dissulfeto. As subunidades alfa estão localizadas inteiramente fora das células e contêm o sítio de ligação de insulina, enquanto, a porção intracelular da subunidade beta, contém atividade de tirosina proteína quinase, regulada pela insulina (White \& Kahn, 1994). O receptor de insulina pode estar presente em todos os tecidos de vertebrados, embora a concentração varie de poucos receptores como 40 nos eritrócitos circulantes até mais de 200.000 nos 
adipócitos e hepatócitos (White \& Kahn, 1994). Scacchi et al. (1988) descreveram a presença de sítios de ligação de insulina em glândulas submandibulares de ratos, usando insulina marcada com ${ }^{125} \mathrm{I}$.

A ligação da insulina à subunidade alfa, induz a uma complexa cascata de fosforilação de tirosinas na subunidade beta. Essa autofosforilação, ativa os receptores para uma tirosina proteína quinase que, por sua vez, fosforila o substrato de receptor de insulina (IRS-1), descrito, inicialmente como fosfoproteína pp 185. Numerosas proteínas identificadas estão potencialmente envolvidas na via de sinalização da insulina se associam ao IRS-1. A insulina também ativa quinases e fosfatases celulares, por meio de mecanismo específico de fosforilação serina/treonina (Laurence, 1992).

A relação da insulina com a síntese de proteínas foi mostrada por Korc et al. (1981), onde a incorporação de $H^{3}$ Leucina em células acinares de pâncreas foi elevada quando se adicionou insulina ao meio de incubação, mostrando que o aumento na incorporação deste aminoácido estaria ligada ao aumento da síntese de proteínas promovido pela insulina. Usando GLSM, Anderson (1988) mostrou que a incorporação do mesmo aminoácido a células acinares em cultura era dose-dependente à insulina e que portanto a síntese de proteínas na GLSM de ratos estaria sob regulação também da insulina.

O tratamento crônico das glândulas salivares com insulina foi estudado por Wang et al. (1994), em animais normais com dose diárias de insulina durante 6 dias, sendo observada hiperplasia e hipertrofia das GLSM 
e GLPA e aumento na incorporação de $H^{3}$ Leucina. Porém, não houve aumento do fluxo salivar estimulado e houve uma redução na atividade da amilase tanto na saliva quanto na GLPA.

\subsubsection{DIABETES E A GLÂNDULA PARÓTIDA}

Trabalhos com animais têm a vantagem de possibilitar o estudo do órgão, como no caso da glândula salivar, e o seu produto, a saliva. Anderson \& Johnson (1981) observaram, em ratos diabéticos, que havia uma redução na atividade da amilase na glândula e na saliva, enquanto a peroxidase estava reduzida somente na saliva. Estes autores atribuíram estas alterações a um possível efeito direto ou indireto da insulina. Para esclarecer esta dúvida, Anderson (1983), estudou o efeito do diabetes na atividade de enzimas secretoras da GLPA em animais diabéticos, obtendo uma redução da atividade da amilase e um aumento da atividade da peroxidase. Quando estes animais foram tratados com doses diárias de insulina, após 7 dias, as atividades desta duas enzimas retornaram a valores normais, mostrando uma possível regulação da insulina sobre estas enzimas. Observações semelhantes foram feitas por Szczepanski et al. (1998) e por Kim et al. (1990), quando após 30 dias da indução do diabetes, os animais apresentaram redução na atividade da amilase na GLPA, a qual foi parcialmente restaurada após a administração de insulina. Neste último estudo, foi verificado também redução na atividade do mRNA para a enzima amilase, sugerindo que a insulina exerce sua atividade na tradução de gene 
dessa enzima. Após 1 dia de tratamento com insulina, os animais apresentavam um aumento na atividade da amilase e da quantidade de seu mRNA. A mesma redução foi verificada por Anderson \& Bevan (1992).

A resposta da GLPA em animais diabéticos, quando estimulada colinergicamente, foi menor do que a comparada a um grupo controle no estudo de Anderson (1987). A resposta secretória foi menor do que no grupo controle, sendo que esta resposta pôde ser restaurada quando estes animais foram tratados com insulina, mostrando que a insulina seria importante na resposta deste estímulo. Estas observações foram confirmadas por Anderson \& Garret (1994). Neste último trabalho os autores mostraram também um aumento na secreção da GLSM após estímulo simpático.

\subsubsection{DIABETES E A GLÂNDULA SUBMANDIBULAR}

Anderson \& Shapiro (1979) realizaram estudo sobre o efeito do diabetes na célula acinar da GLSM de ratos, determinando a atividade da enzima peroxidase, produzida somente nesta célula, tanto na glândula quanto na saliva destes animais. Os autores observaram uma redução da atividade desta enzima tanto na glândula quanto na saliva, sugerindo que a insulina possa ser importante também na manutenção da função deste órgão. 
A severidade do diabetes na secreção de proteínas e saliva da GLSM estimulada parassimpateticamente, em decorrência do tempo, foi verificada por Anderson et al. (1993). Os autores mostraram que dependendo do tempo, o fluxo salivar diminui e a secreção de proteínas não se altera após 3 meses da indução, sendo que o mesmo fluxo salivar e a secreção de proteínas diminui após 6 meses da indução, mostrando que o efeito é dependente do tipo do estímulo e do tempo de duração do diabetes, sendo estes fatores são independentes.

\subsubsection{DIABETES E A SECREÇÃO SALIVAR}

A influência do estado diabético na secreção salivar apresenta resultados conflitantes. Conner et al. (1970) relataram, em adultos diabéticos, uma redução no fluxo salivar na GLPA, quando estimulada com ácido acético, comparada a um grupo controle. Neste estudo os autores escreveram uma frase muito importante: "Não está claro se a xerostomia é o resultado da redução da função da glândula salivar ou uma disfunção, se está relacionada com distúrbios metabólicos remotos provenientes da cavidade oral, representando não necessariamente numa redução da atividade da glândula salivar, ou se existe uma base psíquica." Estas palavras mostram que havia já uma preocupação com a causa da xerostomia descrita nestes indivíduos diabéticos. A redução do fluxo salivar 
também foi observada nos estudos de Kjellman (1970), Banocczy (1987), Harrison \& Bowen (1987), Thorstensson et al. (1997), Chaves et al. (2000).

Em contrapartida, nenhuma redução do fluxo salivar foi confirmada nos estudos de Marder et al. (1975), Sharon et al. (1985), Lamey et al. (1986), Tenovuo et al. (1986a, 1986b), Cherry-Peppers et al. (Streckfus et al. (1994), Doods \& Doods (1997), Meurman et al. (1998).

Streckfus et al. (1994), mostrou uma redução na concentração de proteínas na saliva total em diabéticos. Entretanto aumento da atividade de peroxidase e amilase na saliva de diabéticos foi verificada por Tenovuo et al. (1986a) e por Doods \& Doods (1997), respectivamente.

Nenhuma relação entre a concentração de glicose sangüínea e a salivar foi encontrada por Sharon et al. (1985) ao compararem essas concentrações em pacientes adultos diabéticos e controles.

O controle da glicemia em pacientes foi estudado por Dodds \& Dodds (1997), onde os autores mostraram não haver diferença nos fluxos da saliva total não estimulada, saliva da parótida estimulada e sua concentração de proteínas entre grupos com glicemia controlada e não controlada e entre grupo diabético e controle. Somente a atividade da amilase que se encontrava aumentada no grupo com glicemia não controlada, reduziu com o controle desta glicemia. No entanto, Chaves et al. (2000), encontraram redução do fluxo salivar da saliva total não estimulada, saliva da parótida estimulada e não estimulada em pacientes com controle pobre da glicemia quando comparada a pacientes controles, associando o controle da glicemia com a disfunção salivar em pacientes adultos. 
O estudo de Kimura et al. (1996) mostrou que em animais diabéticos, a resposta máxima ao estímulo $\beta$-adrenérgico e colinérgico muscarínico para a saliva total é menor do que a de grupos controle. Neste trabalho os autores sugerem que a causa da xerostomia seria decorrente a uma disfunção destes receptores nas glândulas salivares.

\subsection{METABOLISMO DE CARBOIDRATOS NO DIABETES}

O primeiro passo da via glicolítica é a fosforilação da molécula de glicose, formando a molécula de glicose-6-fosfato. Esta reação é catalisada pela enzima Hexoquinase (HK), utilizando o ATP como doador de fosfato (Lehninger et al., 1997). A atividade da HK é inibida pelo próprio produto de reação, sendo ativada na falta deste (Champe \& Harvey, 1994).

A compartimentalização da HK mostra-se como importante forma de regulação da enzima. A atividade da HK pode ser controlada pela mudança na ligação da enzima com a mitocôndria. A HK solúvel, apesar de menos ativa, seria importante para o citoplasma da maioria dos tecidos para manter ativa a fosforilação da glicose e a glicólise. Ela seria a responsável pelo início da sua fosforilação; a alteração entre as formas solúvel e ligada seria um importante controle na regulação da atividade desta enzima e sua ação (Anderson et al., 1971). A ligação da HK com a mitocôndria pode ser afetada (Santti e Villee, 1971) ou intermediada (Bessman \& Gots, 1975) pela insulina. O ADP gerado pela mitocôndria na fosforilação da glicose atuaria 
como um estímulo (substrato) para que a mitocôndria realizasse o ciclo de Krebs. A proximidade do gerador de substrato a organela que a utiliza tornaria o processo mais eficiente. A presença do $\mathrm{Mg}$ mostrou sua importância neste processo segundo Viitanen et al. (1984), onde na sua ausência, a ligação a mitocôndrias de músculos esqueléticos de ratos não foi possível.

A ligação da HK cerebral com a mitocôndria durante períodos de stress metabólico, e a seu retorno ao estado solúvel quando este stress é cessado foi mostrado por Knull et al. (1973), indicando que a distribuição da enzima contribui para o controle do metabolismo de carboidratos no cérebro, já que o Km para ATP da forma ligada chega a ser 5 vezes menor do que a forma solúvel $(0,34 \mathrm{mM}$ e $1,7 \mathrm{mM}$ respectivamente).

Relativamente as isoenzimas de $\mathrm{HK}$, a isoenzima II é a que mostra a maior influência ao efeito do diabetes e da insulina em vários tecidos (Katzen, 1966), sendo que esta isoenzima tem sua produção estimulada pela insulina (Osawa et al., 1996). A mesma encontra-se aumentada na fração solúvel de músculos humanos após exercícios moderados, sendo uma resposta ao estímulo da insulina para a captação de glicose observada após o exercício (Koval et al., 1998).

Nas glândulas salivares, a forma predominante encontrada tanto na GLSM quanto na GLPA é a isoenzima I, sendo que também pode ser encontrada a isoenzima II (Knull \& Lamb, 1980). Em animais diabéticos, na GLSM foi verificada a redução das duas isoenzimas. Somente $25 \%$ da HK na GLSM encontram-se na forma ligada, indicando que esta forma não é a 
principal via de regulação da atividade desta enzima neste órgão. A atividade da isoenzima II não apresentou redução em músculos de ratos diabéticos quando comparados a controles. Porém, a taxa de degradação desta enzima foi 3 vezes maior do que a do grupo controle (Frank \& Fromm, 1982) e o tratamento com a insulina fez com que aos valores normais de degradação (Frank \& Formm, 1986).

A GLSM de ratos apresenta a HK distribuída tanto no citosol quanto na fração ligada. Esta ligação pode ser desfeita ou refeita dependendo do estímulo. Um destes estímulos é a epinefrina, que aumenta a porcentagem de HK ligada, enquanto o ATP e a G-6-P são produtos que diminuem após a administração da epinefrina, e retornam a valores normais após 10 minutos (Kodaira \& Yokoyama, 1983).

A segunda enzima regulatória da via glicolítica é a PFK-1. Esta enzima é a responsável pela fosforilação irreversível da molécula de Fru-6$\mathrm{P}$, produzindo a molécula de Fru-1,6- $\mathrm{P}_{2}$, utilizando o ATP como doador de fosfato. Esta enzima tem sua atividade reduzida pelas altas concentrações de ATP e de citrato, sendo ativada pelas altas concentrações de AMP e de Fru-2,6-P 2 (Champe \& Harvey, 1994). Este último produto é gerado pela enzima PFK-2, sendo este o mais importante regulador no fígado e músculo esquelético (Hers, 1982).

A enzima PFK-1 é uma enzima regulada alostericamente. In vitro, suas propriedades cinéticas podem ser determinadas alterando-se o $\mathrm{pH}$ do meio de reação da enzima. $\mathrm{O}$ pH onde a enzima está sujeita a regulação alostérica é o de 7,3 e onde esta regulação é anulada é no pH 8,0 
(Fukushima \& Sugiya, 1992). Segundo Chen-Zion et al. (1992) o pH onde a atividade é máxima é o de 8,2 . $\mathrm{O}$ pH onde a enzima sofre regulação alostérica é o de 6,9 (Nicolau \& Nunez-Burgos, 1991). Nas GLSM de ratos existem 4 isoenzimas (Nicolau \& Nunez-Burgos, 1991) na fração solúvel, porém não há estudos onde possam ser observadas alterações no estado diabético.

Foi mostrado que a PFK-1 apresenta uma forma fosforilada e uma outra não fosforilada, contudo não há relação com a sua atividade nos músculos de ratos (Uyeda et al., 1978). Este estado de fosforilação permite uma maior ligação com o citoesqueleto nestas células musculares (Luther \& Lee, 1986). A insulina é responsável pelo estímulo da ligação da PFK-1 ao citoesqueleto (Chen-Zion et al., 1992).

A enzima PFK-1 foi purificada e caracterizada de GLPA de bovinos por Fukushima \& Sugiya (1992), onde os autores sugerem que o AMP e a Fru-2,6- $\mathrm{P}_{2}$ atuam como reguladores da PFK-1 nas GLPA de bovinos, e o índice de ativação da Fru-2,6- $\mathrm{P}_{2}$ é muito maior do que o AMP. Sua atividade, após a administração de pilocarpina, apresentou-se aumentada, assim como a concentração de Fru-2,6-P 2 e da PFK-2, em GLSM e GLPA de ratos (Nicolau et al., 1992).

Apesar da Fru-2,6- $\mathrm{P}_{2}$, ser um potente ativador da PFK-1 e um inibidor da Fru-1,6- $\mathrm{P}_{2}$, Beitner (1990) afirma que este metabólito não afeta a atividade da HK em tecidos de mamíferos, tão pouco possui ação regulatória em outros tecidos extra-hepáticos como cérebro, pele e músculo 
Em fígado de ratos diabéticos ou mantidos em jejum há uma redução de aproximadamente $20 \%$ no complexo PFK-2/Fru-2,6- $\mathrm{P}_{2}$ ase (Colosia, 1988). Após a administração de insulina ou alimentação, as atividades das enzimas retornam a valores normais. No entanto, a concentração de mRNA destas enzimas encontra-se sem alteração nos 2 casos acima e aumentados cerca de 3 vezes após a alimentação ou administração da insulina. A redução da quantidade das enzimas e seu mRNA sugere uma diminuição na tradução do mRNA e um aumento da degradação da enzima. $\mathrm{O}$ aumento na quantidade de mRNA sugere um sistema dependente de insulina para a expressão dos genes destas enzimas.

A concentração de noradrenalina intracelular mostrou uma aumento na GLSM de camundongos diabéticos 2 semanas após a indução desta, porém, o fluxo salivar se mostrou reduzido, sugerindo que as alterações nos níveis dos neurotransmissores na GLSM e da função secretora parecem mais evidentes nos estágios inicias da doença (Murai et al., 1996).

Murakami , no ano de 1974, verificou a atividade de algumas enzimas do metabolismo de carboidratos em GLSM de ratos diabéticos. Neste estudo o autor mostrou uma redução nas atividades das enzimas HK, LDH e G-6PD e, quando as glândulas foram incubadas com insulina por 3 horas, as atividades destas enzimas retornaram a valores mais altos, mostrando a importância da insulina na regulação desta via da GLSM.

Diante o exposto, muitas dúvidas persistem sobre a influência da insulina e sua falta na regulação do metabolismo de carboidratos nas glândulas salivares de ratos. Alguns estudos mostram uma redução da 
atividade, porém a sua causa ainda é uma incógnita. Não sabemos também de que forma a atividade das enzimas HK e PFK-1 são influenciadas no estado diabéticos, e nem sequer se as são. São dúvidas como estas que justificam o desenvolvimento deste estudo. 


\section{PROPOSIÇÃO}

Os objetivos da presente dissertação foram os de determinar:

1. Determinação da atividade e distribuição da HK entre mitocôndria e citosol no estado diabético e qual a isoenzima afetada;

2. Determinação da atividade e distribuição da PFK-1 entre o citoesqueleto e o citosol e seu estado de inibição;

3. A regulação da PFK-1, pela determinação de PFK-2 e Fru-2,6- $\mathrm{P}_{2}$. 


\section{MATERIAL E MÉTODOS}

\subsection{ANIMAIS}

Ratos adultos (180 - $220 \mathrm{~g})$ da raça Wistar foram utilizados. Os animais foram mantidos em gaiolas individuais durante todo o período experimental, com livre acesso a água e alimento. Os ratos foram divididos em grupos, controle e experimental, e sacrificados de acordo com o experimento a ser desenvolvido (traumatismo craniano). O peso dos animais foi anotado no início e fim do experimento.

\subsection{INDUÇÃO DO DIABETES}

Após um período de jejum de uma noite (aproximadamente 15 horas), os animais receberam uma injeção intravenosa de estreptozotocin (60 mg / Kg de peso corporal) dissolvido em tampão citrato de sódio $0.1 \mathrm{M} \mathrm{pH} \mathrm{4.5.} \mathrm{Os}$ animais do grupo controle receberam somente o veículo.

\subsection{OBTENÇÃO DO MATERIAL}

Os animais foram sacrificados por traumatismo craniano. As glândulas salivares foram imediatamente removidas, limpas de tecido aderente e 
prensadas entre placas de alumínio previamente mantidas em gelo seco e mantidas em freezer $-80^{\circ} \mathrm{C}$ até o momento do uso. Os pesos glandulares foram determinados no dia da utilização.

\subsection{ANÁLISES}

\subsubsection{Determinação da glicemia dos animais}

A glicemia dos animais foi determinada após 48 horas da indução pelo método de Somogyi modificado por Nelson (1944). Foram considerados diabéticos os animais que apresentaram glicemia maior do que $350 \mathrm{mg}$ de glicose $/ 100 \mathrm{ml}$ de sangue. Os animais que apresentavam glicemia menor do que esta, foram novamente submetidos a administração do estreptozotocin. No dia do sacrifício, a glicemia foi novamente determinada, utilizando os mesmos critérios, porém descartamos os animais diabéticos com glicemia menor que $350 \mathrm{mg}$ de glicose/100ml de sangue.

\subsubsection{Determinação da HK Particulada e Solúvel}

A redistribuição da HK entre a forma particulada e solúvel foi determinada pelo método descrito por Knull \& Lamb (1980). Resumidamente consiste no seguinte: as glândulas salivares foram homogeneizadas em solução de sacarose $0,25 \mathrm{M}$ e centrifugadas a $900 \times \mathrm{g}$, em centrífuga refrigerada Sorval modelo $\mathrm{RC2}-\mathrm{B}$, por 10 minutos. $\mathrm{O}$ sedimento foi 
desprezado e o sobrenadante foi centrifugado a 30000 x g por 20 minutos $\mathrm{O}$ sobrenadante desta centrifugação foi considerado como HK solúvel. O sedimento foi ressuspendido em solução de sacarose $0,25 \mathrm{M}$ e centrifugado a $30000 \times \mathrm{g}$ por 10 minutos. O sedimento foi considerado HK particulada e foi solubilizado em solução de sacarose $0,25 \mathrm{M}$ contendo glicose-6-fosfato 1 mM e incubado durante 15 minutos a $25{ }^{\circ} \mathrm{C}$. Após centrifugação a 30000 x g por 20 minutos o sobrenadante foi considerado hexoquinase particulada ou solubilizada.

\subsubsection{Determinação da PFK-1 Solúvel e Ligada ao Citoesqueleto}

A PFK-1 particulada (ligada ao citoesqueleto) e a solúvel foram separadas da seguinte maneira: o tecido congelado foi homogeneizado com solução de sacarose $0,25 \mathrm{M}$ contendo DTT $1 \mathrm{mM}$ e $\mathrm{NaF} 20 \mathrm{mM}$ pH 7,5. O homogenado foi centrifugado a $100 \times \mathrm{g}$ por 5 minutos e o sedimento foi desprezado. O sobrenadante foi centrifugado a $27000 \times \mathrm{g}$, em centrífuga refrigerada Sorval modelo $\mathrm{RC2-B}$, por $15 \mathrm{~min}$. O sobrenadante desta centrifugação foi chamado de fração solúvel, enquanto o sedimento que foi dissolvido na solução homogeneizante, foi considerado como fração particulada. A atividade enzimática das duas frações, foi determinada em dois pHs: pH 8,2 (sob condições máximas em que não está sujeito a regulação alostérica) e pH 6,9 (sob condições sub-ótimas, em que está sujeito a regulação alostérica) como descrito por Nicolau \& Nunez-Burgos (1991). 


\subsubsection{Determinação da PFK-2}

A atividade da PFK-2 (ativa e total) foi determinada pela formação de Fru-2,6- $\mathrm{P}_{2}$, como descrito por Bartrons et al. (1983) e modificado por Nicolau et al. (1992). As glândulas salivares foram homogeneizadas em tampão fosfato $20 \mathrm{mM}, \mathrm{pH}$ 7,5, EDTA $1 \mathrm{mM}$, DTT 1 mM, PMSF 1 mM, KCl 10 mM e glicerol $10 \%$. Após centrifugação a 5000 x g, sob refrigeração, o sobrenadante foi usado para as determinações enzimáticas (ativa e total). Para ambos os ensaios uma alíquota do sobrenadante foi incubado por $20 \mathrm{~min}$. a $30^{\circ} \mathrm{C}$, na presença de ATP $5 \mathrm{mM}$, $\mathrm{MgCl}_{2} 7 \mathrm{mM}, \mathrm{KCl} 100 \mathrm{mM}$. Posteriormente tris $50 \mathrm{mM}$, Pi $1 \mathrm{mM}$, Fru-6-P 5

$\mathrm{mM}$ e G-6-P 17,5 mM foram adicionados e o $\mathrm{pH}$ ajustado a 8,5 para a determinação da atividade total. MES 50 mM, Pi 5 mM, Fru-6-P 1 mM e Glu6-P 3,5 mM estavam presentes e o pH ajustado a 6,6, para a determinação da forma ativa. $\mathrm{O}$ ensaio foi interrompido pela adição de 1 volume de $\mathrm{NaOH}$ 0,1 $\mathrm{M}$ e a Fru-2,6- $\mathrm{P}_{2}$ formada foi determinada.

\subsubsection{Determinação da Fru-2,6- $\mathrm{P}_{2}$}

A atividade da Fru-2,6- $\mathrm{P}_{2}$ foi determinada de acordo com o método de Van Schafting et al. (1982). As glândulas congeladas foram homogeneizadas a $15 \% \mathrm{p} / \mathrm{v}$ em solução de $\mathrm{NaOH}$ 0,1M. o homogenado foi aquecido a $80^{\circ} \mathrm{C}$ por 5 minutos e então neutralizado com ácido acético $0,1 \mathrm{M}$ 
na presença de HEPES $20 \mathrm{mmol} / \mathrm{l}$. Após a centrifugação da mistura a 12.350 x g por 60 minutos, em centrífuga refrigerada Sorval modelo RC2-B, a Fru2,6- $\mathrm{P}_{2}$ na fração sobrenadante foi medida pela ativação do pirofosfato:frutose-6-fosfotransferase preparada pelo método Van Schafting, 1982. A curva padrão foi feita com Fru-2,6-P2 (Sigma, St Louis, MO, USA).

\subsubsection{Determinação de isoenzimas de HK}

As isoenzimas de HK foram determinadas através de cromatografia em DEAE-celulose (Katzen \& Schimke, 1965). As glândulas salivares foram homogeneizadas em $15 \%$ p/v em tampão fosfato de potássio 0,01M contendo sacarose $0,25 \mathrm{M}$, EDTA $5 \mathrm{mM}$, mercaptoetanol $5 \mathrm{mM}$, glicose $10 \mathrm{mM}, \mathrm{pH} 7,0$ e o homogenado centrifugado a $900 \times \mathrm{g}$, sob refrigeração, durante 10 minutos. O sobrenadante foi então centrifugado a $30.000 \times \mathrm{g}$ durante 20 minutos e o sobrenadante resultante foi considerado como contendo HK solúvel. O sedimento, ressuspendido em 1,0 $\mathrm{ml}$ de tampão fosfato, foi centrifugado a $30.000 \times$ g durante 10 minutos. Para solubilização da HK, o sedimento desta última centrifugação foi suspendido em 1,0 ml de tampão fosfato contendo $1 \mathrm{mM}$ de G-6-P e incubado à $25^{\circ} \mathrm{C}$ durante 15 minutos (Chou \& Wilson, 1972). A suspensão foi centrifugada a $30.000 \mathrm{~g}$ durante 20 minutos e o sobrenadante considerado como HK solubilizada. Os dois sobrenadantes contendo HK solúvel e solubilizada foram então aplicados separadamente em uma coluna $(1 \times 4 \mathrm{~cm})$ de DEAE-celulose previamente equilibrada com tampão fosfato. A coluna foi então lavada com 
o mesmo tampão (100 ml) e a enzima eluída usando-se um gradiente linear de 0 a $0,5 \mathrm{M}$ de $\mathrm{KCl}$ em tampão fosfato $(200 \mathrm{ml})$. A atividade da enzima foi determinada em todas as frações.

4.4.7. Determinação de proteína total

A concentração de proteína nos extratos utilizados nas análises foi determinado pelo método de Lowry et al. (1951), usando-se a albumina bovina como padrão.

\subsection{ANÁLISE ESTATÍSTICA}

A análise estatística foi realizada utilizando o teste "t" de Student, com níveis de significância de 5\% e 1\%. 


\section{RESULTADOS}

Os resultados obtidos estão expressos nas tabelas 5.1, 5.2, 5.3, 5.4 e nas figuras $5.1,5.2,5.3,5.4$.

Na tabela 5.1 observamos os valores de glicemia, pesos corporal dos animais dos grupos experimental e controle. Relativamente a glicemia, notamos que o valor médio no grupo controle foi superior a $350 \mathrm{mg}$ de glicose/100ml de sangue, enquanto no grupo controle, este valor esteve abaixo de $100 \mathrm{mg}$ de glicose/100mg de sangue. Podemos notar uma redução estatisticamente significante nos pesos dos animais diabéticos e suas glândulas submandibulares. Entretanto, não houve redução no peso médio das glândulas parótidas. Quando calculamos os pesos glandulares relativos, encontramos somente um aumento estatisticamente significante nas glândulas parótidas.

A tabela 5.2 expressa os resultados das determinações das atividades específicas da enzima HK (na forma solúvel e ligada) em glândulas submandibular e parótida de ratos sacrificados 30 dias após a indução do estado diabético. Nela mostramos uma redução na atividade da HK em GLSM na fração ligada nos animais diabéticos de cerca de $74 \%$ e um 
aumento tanto na fração ligada a mitocôndria (cerca de $85 \%$ ) quanto na solúvel (aproximadamente 33\%) na GLPA desses mesmos animais.

$\mathrm{Na}$ tabela 5.3 estão expressos os resultados da determinação da atividade específica da enzima PFK-1 (na forma solúvel e ligada, sujeito ou não a regulação alostérica) deste mesmo grupo de animais. Observamos um aumento na atividade da PFK-1 somente na GLSM no pH 6,9 (sujeito a regulação alostérica) na GLSM nas frações solúvel (aproximadamente 50\%) e ligada a mitocôndria (aproximadamente 84\%).

$\mathrm{Na}$ tabela 5.4 estão expressos os resultados das analises das atividade da PFK-2 (nas formas totais e ativas) e do metabólito Fru-2,6- $\mathrm{P}_{2}$ na glândula submandibular. Podemos notar uma redução na atividade dessa enzima, tanto na forma ativa (cerca de 44\%) quanto na total (aproximadamente $28 \%$ ). Podemos observar também que a porcentagem da enzima no estado ativo do grupo diabético foi menor $(35,97 \%)$ do que no grupo controle $(46,41 \%)$. A quantidade de Fru-2,6- $\mathrm{P}_{2}$ também mostrou uma redução de cerca de $42 \%$.

A figura 5.1 mostra o perfil de eluições da enzima HK solúvel enquanto a figura 5.2 mostra o perfil de eluição da HK ligada a mitocôndria de glândulas submandibulares de ratos diabéticos e controles. Na figura 5.1 observamos no grupo controle a presença de 2 isoenzimas, uma entre as frações 29 e 41 , e outra entre 43 e 52 . No grupo experimental, notamos a presença de somente 1 isoenzima nas eluições 43 a 45 . Na figura 5.2 observamos a presença de 2 isoenzimas (eluição 37 e 39) enquanto no grupo experimental somente 1 pico de atividade nas frações 39 e 40 
É possível observar que uma forma isoenzimática da enzima HK é detectada no líquido de lavagem da coluna (eluições 1 a 23) em todas as preparações.

A figura 5.3 mostra o perfil de eluições da enzima HK solúvel enquanto a figura 5.4 mostra o perfil de eluição da HK ligada a mitocôndria de glândulas parótida de ratos diabéticos e controles. Na figura 5.3 podemos notar a presença de somente 1 pico de atividade nos 2 grupos. No controle ele se encontra entre as eluições 35 e 58, enquanto no experimental entre as eluições 41 e 46 . A figura 5.4 mostra também somente 1 pico de atividade no grupo controle entre as eluições 34 e 37 enquanto no grupo experimental este pico encontra-se na eluição 72. 
Tabela 5.1 - Glicemia, pesos corpóreo inicial, final, glandular e relativo (PGR) de ratos diabéticos (D) sacrificados 30 dias após a indução com estreptozotocin e controle $(C)$. O asterisco indica diferença estatisticamente significante, pelo teste $t$ de Student $\left({ }^{*} p<0,05 e^{* *} p<0,01\right)$.

\begin{tabular}{|c|c|c|c|c|c|c|c|}
\hline \multirow{3}{*}{ Grupos } & \multirow{3}{*}{$\begin{array}{c}\text { Glicemia } \\
\text { (mg glicose/dl } \\
\text { sangue) }\end{array}$} & \multicolumn{2}{|c|}{ Peso Corporal } & \multicolumn{4}{|c|}{ Peso Glandular } \\
\hline & & \multirow{2}{*}{ Inicial } & \multirow{2}{*}{ Final } & \multicolumn{2}{|c|}{ SM } & \multicolumn{2}{|c|}{ PA } \\
\hline & & & & $\mathrm{mg}$ & PGR & $\mathrm{mg}$ & PGR \\
\hline D & $\begin{array}{c}439 \pm 120 \\
(n=36) *\end{array}$ & $\begin{array}{c}215,1 \pm 28 \\
(n=36)\end{array}$ & $\begin{array}{c}180,6 \pm 24,6 \\
(n=36) *\end{array}$ & $\begin{array}{c}121,7 \pm 10,2 \\
(n=36) *\end{array}$ & $\begin{array}{c}0,067 \pm 0,005 \\
(n=36)\end{array}$ & $\begin{array}{c}115,45 \pm 8,2 \\
(n=36)\end{array}$ & $\begin{array}{c}0,06 \pm 0,01 \\
(n=36) *\end{array}$ \\
\hline C & $\begin{array}{c}77,5 \pm 23,6 \\
(n=36)\end{array}$ & $\begin{array}{c}192 \pm 27,52 \\
(n=36)\end{array}$ & $\begin{array}{c}261,3 \pm 45,6 \\
(n=36)\end{array}$ & $\begin{array}{c}183,1 \pm 27,4 \\
(n=36)\end{array}$ & $\begin{array}{c}0,070 \pm 0,007 \\
(n=36)\end{array}$ & $\begin{array}{c}93,84 \pm 10,90 \\
(n=36)\end{array}$ & $\begin{array}{c}0,03 \pm 0,007 \\
(n=36)\end{array}$ \\
\hline
\end{tabular}


Tabela 5.2 - Atividade específica da Hexoquinase (HK), nos estados solúvel (S) e ligado (L) a mitocôndria, em glândulas submandibular (SM) e parótida (PA) de ratos diabéticos (D) induzida por estreptozotocin, e de controles (C), sacrificados 30 dias após a indução do diabetes. O asterisco indica diferença estatisticamente significante, pelo teste t de Student $\left({ }^{*} p<0,05\right.$ $\left.e^{* *} p<0,01\right)$.

\begin{tabular}{|c|c|c|c|}
\hline \multicolumn{4}{|c|}{ HK (mU/mg de proteína) } \\
\hline \multirow[b]{2}{*}{ GRUPOS } & \multicolumn{3}{|c|}{ SM } \\
\hline & $S$ & L & $S+L$ \\
\hline $\mathrm{D}$ & $\begin{array}{c}17,4 \pm 5,4 \\
n=9\end{array}$ & $\begin{array}{c}23,5 \pm 7,6 \text { ** } \\
n=8\end{array}$ & $40,9 \pm 13$ \\
\hline \multirow[t]{2}{*}{ C } & $\begin{array}{c}17,0 \pm 5,5 \\
n=9\end{array}$ & $\begin{aligned} 91,6 & \pm 13,7 \\
\mathrm{n} & =8\end{aligned}$ & $107,6 \pm 19,2$ \\
\hline & \multicolumn{3}{|c|}{ PA } \\
\hline GRUPOS & S & L & $S+L$ \\
\hline D & $\begin{array}{c}12,3 \pm 3,3 \text { * } \\
n=11\end{array}$ & $\begin{array}{c}14,8 \pm 2,0 \text { ** } \\
n=8\end{array}$ & $27,1 \pm 5,3$ \\
\hline C & $\begin{array}{c}9,2 \pm 2,9 \\
\mathrm{n}=11\end{array}$ & $\begin{array}{c}8,0 \pm 2,2 \\
n=11\end{array}$ & $17,2 \pm 5,1$ \\
\hline
\end{tabular}


Tabela 5.3 - Distribuição da PFK-1, expressa em $\mathrm{mU} / \mathrm{mg}$ de proteína, entre as frações solúvel (S) e ligada (L) ao citoesqueleto, no pH 6,9 (sujeito a regulação alostérica) e no pH 8,2 (não sujeito a regulação alostérica), em glândulas submandibular e parótida de ratos diabéticos (D) induzida por estreptozotocin, e de controles (C), sacrificados 30 dias após a indução do diabetes. O asterisco indica diferença estatisticamente significante, pelo teste t de Student $\left({ }^{*} p<0,05 e^{* *} p<0,01\right)$.

\begin{tabular}{|c|c|c|c|c|c|c|}
\hline \multicolumn{7}{|c|}{ PFK (mU/mg de proteína) } \\
\hline \multirow[b]{3}{*}{ GRUPOS } & \multicolumn{6}{|c|}{ SM } \\
\hline & \multicolumn{3}{|c|}{$\mathrm{pH} \mathrm{6,9}$} & \multicolumn{3}{|c|}{$\mathrm{pH} 8,2$} \\
\hline & $S$ & L & $S+L$ & S & L & $S+L$ \\
\hline D & $\begin{array}{c}11,4 \pm 3,2 * \\
n=9\end{array}$ & $\begin{array}{c}55,6 \pm 7,2 * \\
\mathrm{n}=9\end{array}$ & $67,0 \pm 10,4$ & $\begin{array}{c}6,9 \pm 1,8 \\
n=10\end{array}$ & $\begin{array}{c}47,5 \pm 15,6 \\
\mathrm{n}=8\end{array}$ & $54,4 \pm 17,4$ \\
\hline \multirow[t]{3}{*}{ C } & $\begin{array}{c}7,6 \pm 1,9 \\
\mathrm{n}=8\end{array}$ & $\begin{array}{c}30,1 \pm 9,0 \\
\mathrm{n}=8\end{array}$ & $37,6 \pm 10,9$ & $\begin{array}{c}7,2 \pm 2,4 \\
n=10 \\
\end{array}$ & $\begin{aligned} 53,9 & \pm 10,9 \\
n & =8\end{aligned}$ & $61,1 \pm 13,3$ \\
\hline & \multicolumn{6}{|c|}{ PA } \\
\hline & \multicolumn{3}{|c|}{$\mathrm{pH} \mathrm{6,9}$} & \multicolumn{3}{|c|}{$\mathrm{pH} 8,2$} \\
\hline GRUPOS & $S$ & L & $S+L$ & S & L & $S+L$ \\
\hline D & $\begin{array}{c}5,7 \pm 1,1 \\
n=10\end{array}$ & $\begin{array}{c}19,3 \pm 5,0 \\
n=10\end{array}$ & $30,7 \pm 8,2$ & $\begin{array}{c}36,4 \pm 8,2 \\
n=10\end{array}$ & $\begin{array}{c}28,1 \pm 8,9 \\
n=9\end{array}$ & $64,5 \pm 17,1$ \\
\hline C & $\begin{array}{c}6,4 \pm 1,6 \\
n=8\end{array}$ & $\begin{array}{c}18,6 \pm 5,0 \\
n=11\end{array}$ & $26,2 \pm 6,9$ & $\begin{array}{c}35,1 \pm 9,9 \\
n=8\end{array}$ & $\begin{array}{c}34,4 \pm 7,7 \\
\mathrm{n}=10\end{array}$ & $69,5 \pm 16,6$ \\
\hline
\end{tabular}


Tabela 5,4 - Atividade específica da PFK-2 e conteúdo de Fru-2,6-P 2 em glândulas submandibulares de ratos diabéticos (D) induzida por estreptozotocin, e de controles $(C)$, sacrificados 30 dias após a indução do diabetes. O asterisco indica diferença estatisticamente significante pelo teste $t$ de Student $\left({ }^{* *} p<0,01\right)$.

\begin{tabular}{|c|c|c|c|c|}
\hline \multirow[b]{2}{*}{ GRUPOS } & \multirow{2}{*}{$\begin{array}{c}\text { Fru-2,6- } \mathrm{P}_{2} \\
\text { (pmol/g tec/min) }\end{array}$} & \multicolumn{3}{|c|}{ PFK-2 } \\
\hline & & $\begin{array}{c}\text { Total } \\
\text { (pmol/g } \\
\text { tec/min) }\end{array}$ & $\begin{array}{c}\text { Ativa } \\
\text { (pmol/g } \\
\text { tec/min) }\end{array}$ & $\begin{array}{l}\text { Relação } \\
\text { Ativa/Total }\end{array}$ \\
\hline $\mathrm{D}$ & $\begin{array}{c}50,20 \pm 7,58 \text { ** } \\
(12)\end{array}$ & $\begin{array}{c}19,96 \pm 5,47^{* *} \\
(20)\end{array}$ & $\begin{array}{c}7,18 \pm 1,71^{* *} \\
(13)\end{array}$ & $35,97 \%$ \\
\hline C & $\begin{array}{c}87,2 \pm 16,8 \\
(8)\end{array}$ & $\begin{array}{l}27,92 \pm 8,23 \\
(20)\end{array}$ & $\begin{array}{c}12,96 \pm 1,70 \\
(13)\end{array}$ & $46,41 \%$ \\
\hline
\end{tabular}


Figura 5.1 - Perfil cromatográfico da HK solúvel de glândula submandibular (controle e diabético), após passagem em coluna de DEAE-Celulose $(1 \times 4 \mathrm{~cm})$ e eluída em gradiente linear de $\mathrm{KCl}(0-0,5 \mathrm{M})$ em tampão fosfato, e coletado em frações de 3 $\mathrm{ml}$.

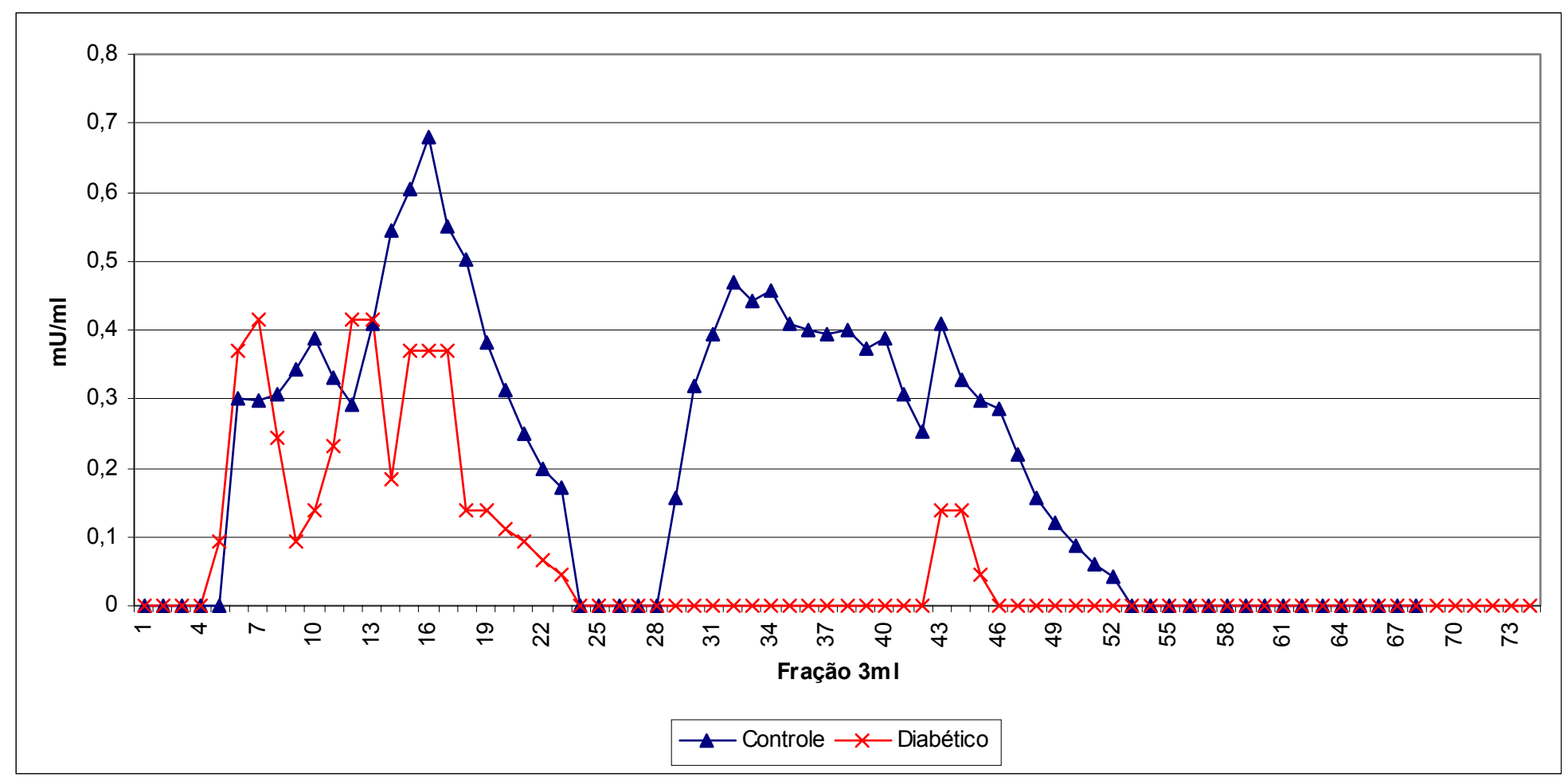


Figura 5.2 - Perfil cromatográfico da HK ligada de glândula submandibular (controle e diabético), após passagem em coluna de DEAE-Celulose $(1 \times 4 \mathrm{~cm})$ e eluída em gradiente linear de $\mathrm{KCl}(0-0,5 \mathrm{M})$ em tampão fosfato, e coletado em frações de 3 $\mathrm{ml}$.

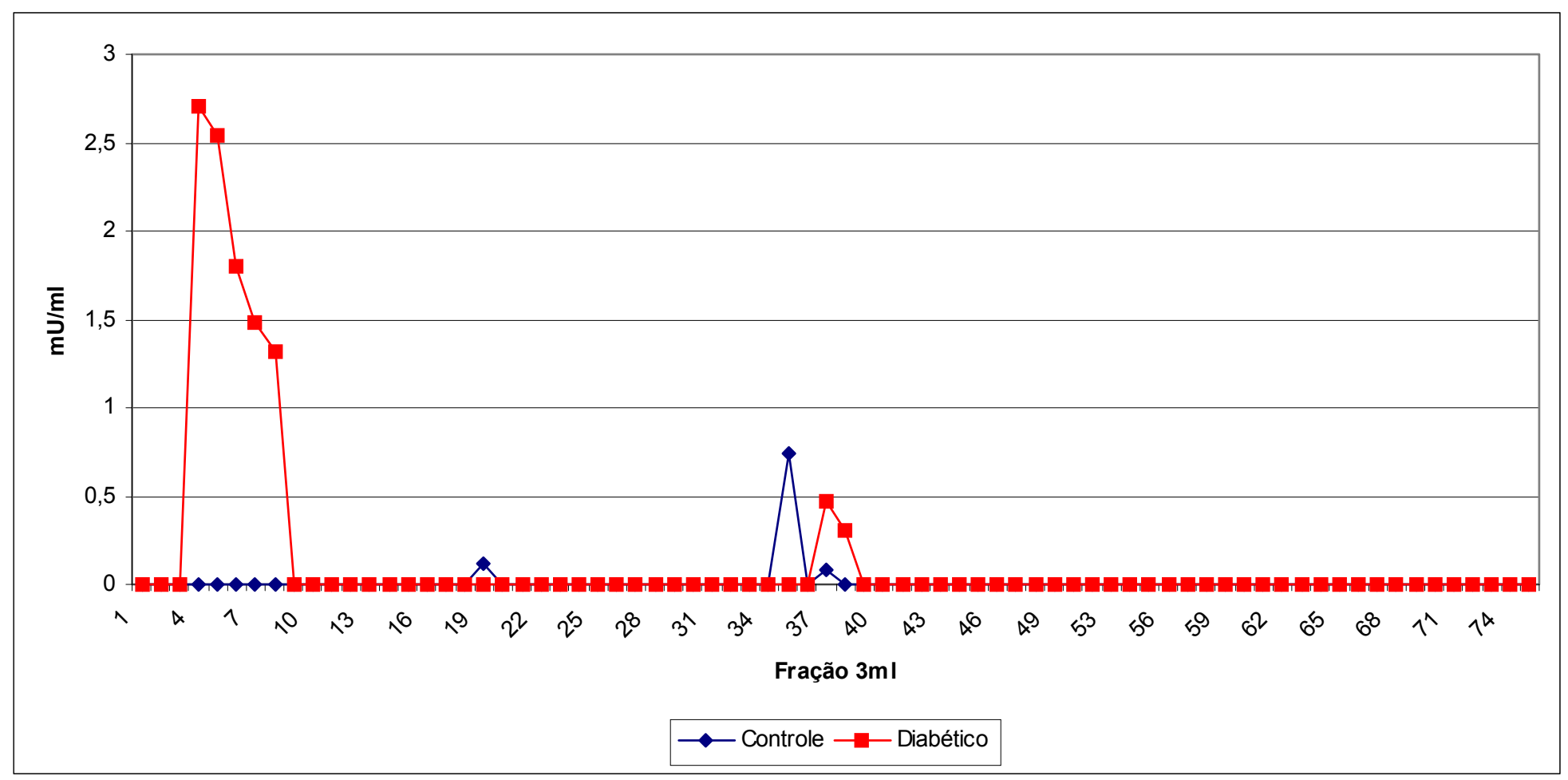


Figura 5.3 - Perfil cromatográfico da HK solúvel de glândula parótida (controle e diabético), após passagem em coluna de DEAE-Celulose $(1 \times 4 \mathrm{~cm})$ e eluída em gradiente linear de $\mathrm{KCl}(0-0,5 \mathrm{M})$ em tampão fosfato, e coletado em frações de $3 \mathrm{ml}$.

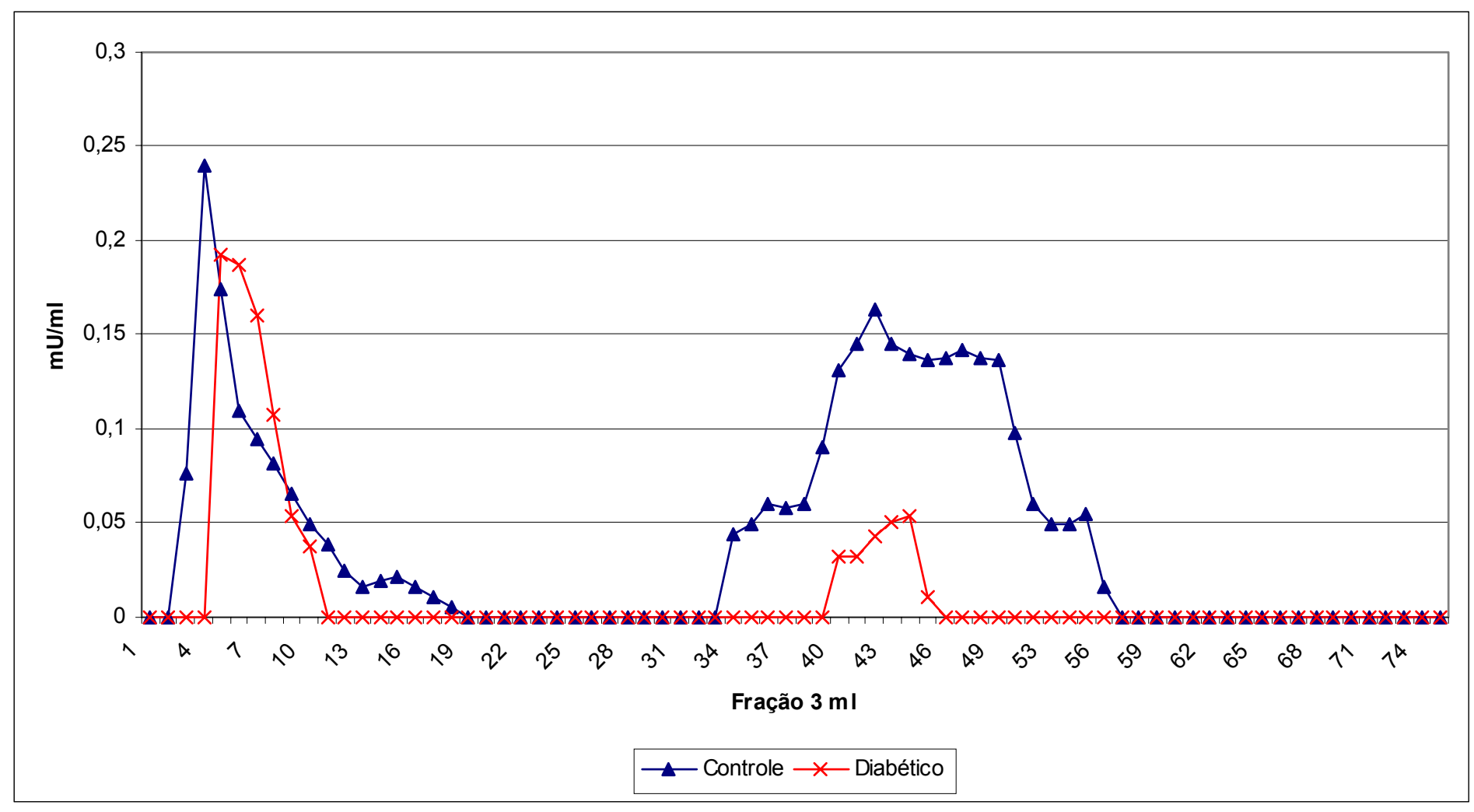


Figura 5.4 - Perfil cromatográfico da HK ligada de glândula parótida (controle e diabético), após passagem em coluna de DEAE-Celulose $(1 \times 4 \mathrm{~cm})$ e eluída em gradiente linear de $\mathrm{KCl}(0-0,5 \mathrm{M})$ em tampão fosfato, e coletado em frações de $3 \mathrm{ml}$.

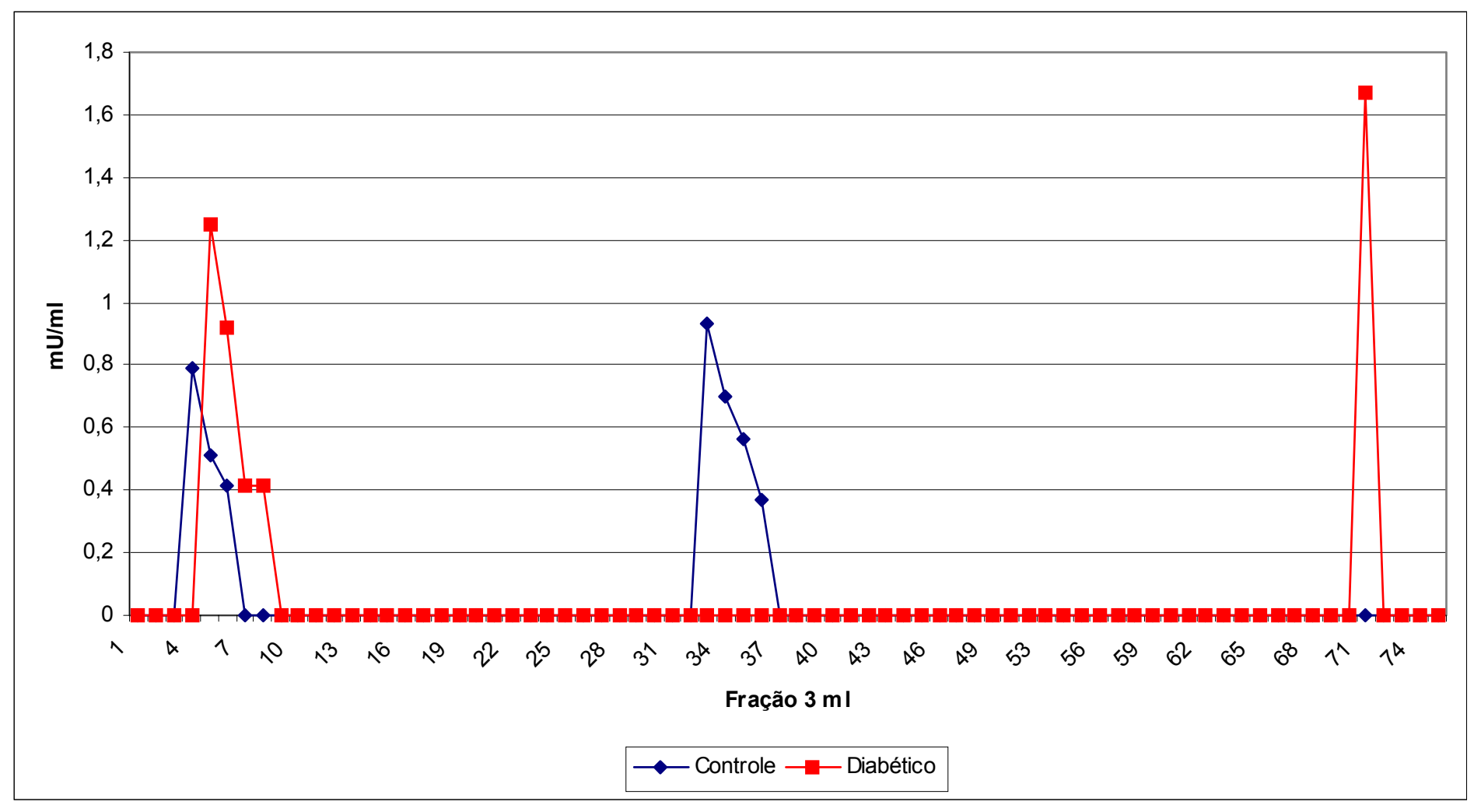




\section{DISCUSSÃO}

Embora o peso corpóreo médio dos animais do grupo experimental tenham sofrido uma redução de aproximadamente $16 \%$, contra um aumento do grupo controle de cerca de $36 \%$, o peso glandular relativo das glândulas submandibulares não apresentou diferença. Isto indica que na presente pesquisa não houve ocorrência de hipertrofia e hiperplasia. Por outro lado, examinando-se o peso glandular relativo das glândulas parótidas, observase que o mesmo é maior no grupo experimental do que no controle. Esse resultado indica que, provavelmente, isto é devido a processo de hipertrofia e hiperplasia os quais já haviam sido relatados por Anderson \& Johnson (1981).

A fim de fazermos algumas considerações acerca dos dados obtidos no presente estudo, abordaremos o esquema metabólico a seguir: 


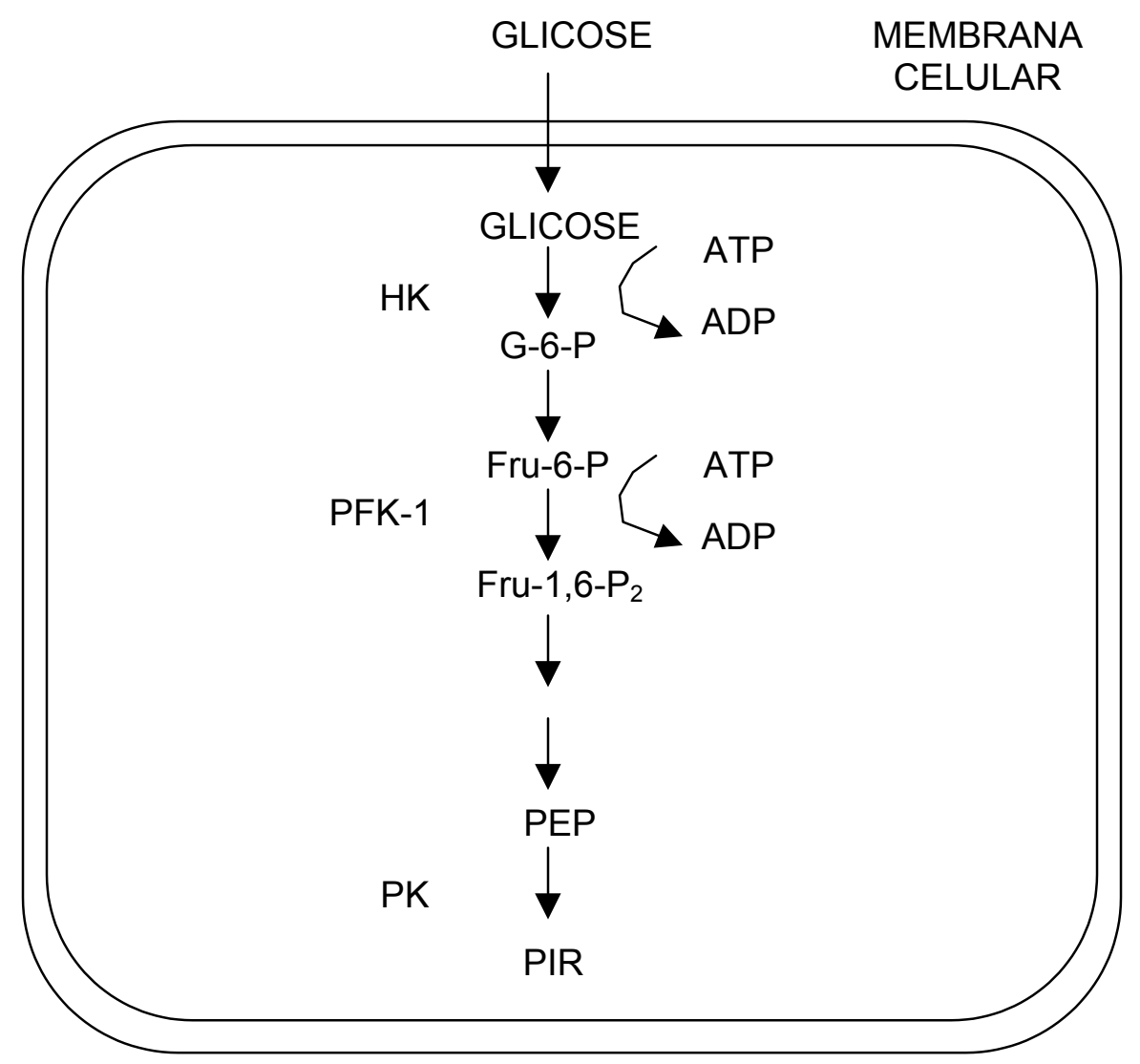

A via glicolítica é utilizada pelos tecidos para a metabolização da glicose produzindo energia na forma da ATP. Após sua entrada na célula a glicose é fosforilada pela enzima HK, produzindo a G-6-P, a qual é importante para o fluxo metabólito e para impedir a sua saída da célula. Sua atividade é inibida pelo aumento na concentração do produto da reação, ou seja pela concentração da própria G-6-P (Champe \& Harvey, 1994).

$$
\mathrm{G}+\mathrm{ATP} \stackrel{\mathrm{HK}}{\longrightarrow} \mathrm{G}-6-\mathrm{P}+\mathrm{ADP}
$$


A segunda enzima regulatória é a PFK-1. Ela é a responsável pela fosforilação irreversível da Fru-6-P, formando a Fru-1,6- $\mathrm{P}_{2}$, sendo considerada um ponto importante na regulação da via glicolítica.

$$
\mathrm{F}-6-\mathrm{P}+\mathrm{ATP} \stackrel{\mathrm{PFK}-1}{\longrightarrow} \mathrm{Fru}-1,6-\mathrm{P}_{2}+\mathrm{ADP}
$$

A atividade desta enzima é regulada por alguns fatores, tais como a concentração dos substratos ATP e Fru-6-P (Champe \& Harvey, 1994). Outra forma de regulação ocorre pelos níveis de energia da célula, ou seja, pela concentração de ATP. A alta concentração de ATP seria resultado de um excesso de produção de energia que resultaria na diminuição de atividade desta enzima. Altas concentrações de citrato, proveniente do ciclo de Krebs, agiriam desta mesma forma. Um tipo de regulação muito importante é a realizada pela Fru-2,6- $\mathrm{P}_{2}$. Este metabólito é um potente ativador da PFK-1 (Champe \& Harvey, 1994). A Fru-2,6- $\mathrm{P}_{2}$ é produzida pela PFK-2, que converte a Fru-6-P em Fru-2,6- $\mathrm{P}_{2}$. A enzima PFK-2 tem sua atividade regulada pela insulina e pelo glucagon. Altos níveis de glucagon e baixos de insulina ativam a adenilato ciclase, produzindo cAMP, que por sua vez ativa a proteína quinase A, que desfosforila a enzima PFK-2, inibindo a forma quinase da enzima, reduzindo por conseqüência a formação da Fru2,6- $\mathrm{P}_{2}$, inibindo a via glicolítica, ativando a gliconeogênese. Este processo ocorre nos períodos de jejum. O inverso ocorre nos períodos de alimentação, onde a glicose está em abundância, havendo um aumento de atividade da via glicolítica. 


$$
\text { F-6-P + ATP } \stackrel{\text { PFK-2 }}{\longrightarrow} \text { Fru-2,6- } \mathrm{P}_{2}+\text { ADP }
$$

A terceira e última enzima regulatória é a PK. Ela é a responsável pela defosforilação irreversível do fosfoenolpiruvato formando o piruvato. Sua atividade é regulada pela presença de ATP. No fígado, esta enzima é ativada pela Fru-1,6-P 2 . Ou seja, no fígado, o aumento da atividade da PFK1 leva a um aumenta da atividade da PK (Champe \& Harvey, 1994).

$$
\mathrm{PEP}+\mathrm{ADP} \stackrel{\mathrm{PK}}{\longrightarrow} \mathrm{PIR}+\mathrm{ATP}
$$

Entre as formas de regulação da atividade enzimática, podemos citar: (a) a distribuição entre formas solúvel e ligada; (b) a regulação alostérica, isto é, por metabólitos formados na própria célula; (c) ligação covalente, como é o caso de fosforilação e defosfrilação de algumas enzimas.

Tanto a HK quanto a PFK-1 podem ser encontradas na fração solúvel e na ligada a mitocôndria (caso da HK) ou citoesqueleto (caso da PFK-1). Isto proporciona um tipo de regulação importante dentro da célula. Laursen et al. (1990) mostraram que o valor do Km da HK para o ATP chega a ser 5 vezes maior na forma solúvel quando comparado a forma ligada, e este aumento no Km leva a uma menor atividade desta enzima.

As glândulas submandibular e parótida possuem características metabólicas diferentes. Enquanto a glândula submandibular apresenta um 
metabolismo com predominância da via anaeróbica, a glândula parótida apresenta um metabolismo onde predomina a via aeróbica (Nicolau \& Sassaki, 1976), daí a discussão das 2 glândulas serem feitas separadamente.

Em glândula parótida, não é de nosso conhecimento na literatura da influência do diabetes sobre a atividade da HK, porém o aumento da atividade mostrado em nosso estudo pode ser comparado ao estudo de Sochor et al. (1990) que mostrou aumento na atividade em olhos e pulmão de ratos diabéticos de aproximadamente $40 \%$, um pouco maior do que os cerca de $33 \%$ aqui descritos. Na fração ligada a mitocôndria, o aumento de cerca de $83 \%$ é maior do que o encontrado em olhos (52\%) e pulmão (51\%) deste mesmo estudo. Os autores afirmam que a influência do estado diabético na atividade da enzima HK varia conforme a necessidade de insulina nesse tecido para a ocorrência da fosforilação da glicose, o que varia nos tecidos do organismo.

O aumento na atividade da enzima HK encontrado na glândula parótida nas frações solúvel e ligada demonstra que mesmo na ausência da insulina, houve um aumento da atividade da HK, sugerindo que outros fatores podem ser responsáveis por este aumento de atividade.

Em glândulas submandibulares, Murakami (1974) já havia relatado redução na atividade da HK na fração solúvel de ratos diabéticos de cerca de 35\%. Knull \& Lamb (1980) mostraram diminuição de cerca de $21 \%$ de atividade na fração solúvel, sendo que esta fração corresponde a cerca de $53 \%$ do total de enzima na glândula submandibular de ratos normais 
(Kodaira e Yokoyama, 1983). A redução de cerca de $74 \%$ encontrada por nós somente na fração ligada a mitocôndria confirma as observações destes autores sendo muito semelhante ao valor encontrado em glândulas mamárias no estudo de Sochor et al. (1990), que foi de 73\%. Porém, a não alteração na atividade da fração solúvel não encontra paralelo na literatura, pois tanto no estudo de Murakami (1974) quanto no de Knull \& Lamb (1980), os autores determinaram atividade enzimática total, não discriminando se fração solúvel ou ligada a mitocôndria. Além disso, o período de indução do diabetes nestes estudos é menor do que o utilizado por nós. Redução de atividade da $\mathrm{HK}$ foi também encontrada em alguns tecidos de ratos diabéticos (Sochor et al., 1990), entre eles: fígado (fração solúvel e ligada), glândula mamária (fração solúvel e ligada), tecido adiposo (fração solúvel e ligada), coração (fração ligada) e artéria aorta (fração ligada). Redução na atividade da HK em músculos de ratos diabéticos foi verificada por Frank \& Fromm (1986).

Conforme demonstrado por Knull \& Lamb (1980), a isoenzima de HK predominante tanto na GLPA quanto na GLSM em ratos normais é a I, sendo também encontrada a II em ambas, entretanto, somente traços desta isoenzima foi encontrado na GLPA. No estado diabético, a isoenzima II é a mais susceptível a redução de atividade (Sochor et al., 1990; Frank \& Fromm, 1986). Podemos afirmar ter encontrados na GLSM dos animais controles, tanto na fração solúvel quanto na ligada a mitocôndria, 2 isoenzimas durante a cromatografia e um terceiro pico, ainda no líquido de lavagem, que mostrou grande atividade em todos os experimentos. Nos 
animais experimentais, foi encontrado somente 1 pico de atividade na cromatografia na GLSM, sugerindo a inibição da atividade de alguma das isoenzima nos animais diabéticos. Frank \& From (1986), relataram que no músculo esquelético de ratos diabéticos, há uma diminuição na taxa de síntese um aumento na taxa de degradação da isoenzima II.

Nas GLPA, nos animais controle foi encontrada somente uma isoenzima tanto na fração solúvel quanto na ligada. Porém o mesmo pico com atividade durante a lavagem da coluna foi encontrado. Na fração solúvel de animais experimentais, não há diferença no padrão da isoenzima. Entretanto, na fração ligada, há uma diferença do padrão cromatográfico, podendo-se suspeitar que sejam isoenzimas diferentes.

Não é de nosso conhecimento estudos sobre a influência do estado diabético na atividade da PFK-1 nas glândulas salivares.

Trabalhando com linfócitos do timo de ratos diabéticos induzidos por estreptozotocin, Moreno-Aurioles et al. (1996) relataram aumento da atividade da PFK-1, provavelmente devido ao aumento da atividade da PFK2 e consequentemente, do conteúdo de Fru-2,6- $\mathrm{P}_{2}$. Em nosso trabalho, determinamos, em glândula submandibular, a atividade da PFK-2 e o conteúdo de Fru-2,6-P 2 . Observamos redução da atividade da PFK-2 de aproximadamente $44 \%$, enquanto o conteúdo de Fru-2,6- $\mathrm{P}_{2}$ apresentou redução de $42 \%$.

Considerando-se que a atividade de PFK-1 é regulada alostericamente pela Fru-2,6- $\mathrm{P}_{2}$, deveríamos ter observado uma redução da atividade da PFK-1, em GLSM de ratos. Não foi o que verificamos. Nossos 
resultados mostram um aumento de cerca de $33 \%$ na atividade da enzima PFK-1 determinada na fração solúvel e de mais ou menos $45 \%$ na atividade da fração ligada ao citoesqueleto.

Uma explicação para esses achados, provavelmente, seria o fato que, em animais diabéticos induzido por estreptozotocin, existe a destruição das células $\beta$ do pâncreas, produtoras da insulina, mas não das células $\alpha$, produtoras do glucagon. É sabido que o aumento do teor de glucagon acarretaria, em alguns tecidos, a estimulação do sistema cAMP-adenilato ciclase, e como conseqüência, a fosforilação de algumas enzimas. A forma quinase da PFK-2 é defosforilada, enquanto a forma fosfatase é fosforilada. Com o aumento da relação glucagon/insulina, é provável a fosforilação da PFK-2, via proteína quinase dependente de cAMP. Dessa forma, o aumento observado na atividade da enzima PFK-1 seria devido, provavelmente, a outros meios que não a PFK-2 e a Fru-2,6- $\mathrm{P}_{2}$. Além disso, assim como na HK, a PFK-1 tem sua atividade influenciada diferentemente nos diversos tecidos a ação da insulina. Redução da atividade da PFK-1 em fígado, coração e rins de ratos diabéticos, induzido pelo estreptozotocin, foi citado por Moreno-Aurioles et al. (1996). As mesmas observações foram feitas por Marynissen et al. (1989), que mostrou redução da atividade da PFK-1 em fígado, porém, com o aumento da concentração de glicose no interior deste órgão, os autores acreditam que a redução da atividade não acarrete nenhuma alteração das propriedades cinéticas da PFK-1. Em contrapartida, Hotta et al. (1996), não observaram alteração na atividade da PFK-1 em fígado de ratos (OLETF) animais geneticamente diabéticos do tipo II (não- 
insulino dependentes). Em cérebro de ratos diabéticos, Srivastava \& Baquer (1984), encontrou redução na atividade da PFK-1 em algumas regiões (hemisférios e cerebelo), sugerindo que estas reduções se deviam a um aumento na concentração de citrato, que por sua vez seria divida a um acúmulo de ATP nas células.

Considerando-se a forma determinada em $\mathrm{pH} 8,2$ e portanto não sujeita a regulação alostérica, não foi possível observar variação entre os grupos experimental e controle.

Relativamente à GLPA, observamos um aumento da atividade da HK tanto na fração solúvel quanto na ligada a mitocôndria, mas a atividade da PFK-1 não apresentou diferenças entre os grupos controle e experimental.

Em humanos, durante o repouso, a produção de saliva pela GLPA chega a ser nula. Com o estímulo mastigatório, e contribuição dessa glândula chega a ser $50 \%$ do total de saliva presente na cavidade oral (Tenovuo, 1989). A polifagia, um dos sintomas nos indivíduos diabéticos, ocorre também nos animais (Anderson \& Johnson, 1981, Anderson, 1983). O aumento na atividade da HK pode estar relacionado ao maior estímulo, tanto mecânico quanto gustatório, oferecidos pelos animais. Sendo assim, esta glândula, com metabolismo predominantemente aeróbico, outros fatores devam ser responsáveis pelo aumento da atividade da $\mathrm{HK}$ e não redução da atividade da PFK-1. Conforme já relatado, a isoenzima predominante na GLPA é a I, que justamente sofre menor influência no estado diabético, daí a resposta para a não observância na redução de formas isoenzimáticas nesta glândula. Este aumento da atividade da HK 
manteria normal a concentração de G-6-P, permitindo que esta via glicolítica e consequentemente a glândula funcione normalmente.

Na glândula submandibular, a redução na atividade da HK na fração ligada a mitocôndria mostra que, a presença da isoenzima II, justamente sujeita a maiores alterações no estado diabético, pode ser a responsável pela diminuição de atividade dessa enzima na glândula, já que houve a redução de uma forma isoenzimática no estado diabético. A redução da atividade da HK, geraria uma menor quantidade G-6-P, que após ser convertido em Fru-6-P, serviria de substrato para a enzima PFK-1, a qual encontrou sua atividade aumentada na fração solúvel sujeita e não a regulação alostérica. O aumento na atividade da PFK-1 pode ser decorrente de uma redução da concentração de ATP na célula, em decorrência da redução de atividade da HK, que diminuiria a concentração de substrato para as demais reações. Além disso, na fração solúvel, a PFK-1 não estaria sujeita a nenhuma regulação alostérica. Podemos afirmar também que a insulina não é a responsável pela ligação da PFK-1 ao citoesqueleto, por não encontrarmos qualquer alteração em sua atividade na fração ligada.

O aumento da atividade da enzima PFK-1, observada na glândula submandibular, sujeita a controle alostérico, quando confrontada a redução da quantidade de Fru-2,6- $\mathrm{P}_{2}$, mostra uma ausência de regulação por este, diferente de outros estudos, que observaram sempre redução da concentração da Fru-2,- $\mathrm{P}_{2}$ concomitante a redução da atividade da PFK-1 em outros tecidos. (Moreno-Aurioles et al., 1996; Marynissen et al., 1989; 
Madsen et al., 1995); supondo que a PFK-1 possa ter sua atividade regulada por outros fatores nesta glândula.

Segundo Fell (2000), “alterações fisiológicas no fluxo metabólico necessitam de alterações similares na atividade de todas ou na maioria das enzimas esta via". Baseado nisso, maiores estudos são necessários nesta área, determinando-se as alterações de todas as enzimas da via glicolítica, para a verificação da total influência do estado diabético na atividade das glândulas salivares. 


\section{CONCLUSÕES}

A análise e discussão dos resultados obtidos no presente trabalho, permitiram-nos concluir que em ratos diabéticos sacrificados 30 dias após a indução:

1. O aumento na atividade da HK observado na glândula parótida tanto na fração solúvel quanto na fração ligada a mitocôndria pode ser devido a outros fatores que não a insulina. A redução da atividade da HK observada na glândula submandibular na fração ligada a mitocôndria pode estar relacionada a falta de estímulo da insulina no animal.

2. Não há alteração nas formas isoenzimáticas de HK na glândula parótida no estado diabético. Entretanto, existe redução de uma forma isoenzimática de HK tanto na forma solúvel quanto na forma ligada a mitocôndria na glândula submandibular.

3. A falta da insulina não influencia a atividade da enzima PFK-1 na glândula parótida. Contudo, o aumento da atividade da PFK-1, na forma solúvel e na forma ligada, em condições sujeita ao controle alostérico observada da glândula submandibular, pode ser devido a fatores outros que não a insulina, tão pouco o metabólito Fru-2,6- $\mathrm{P}_{2}$. 


\section{REFERÊNCIAS BIBLIOGRÁFICAS *}

ANDERSON, L. C. Effects of alloxan diabetes and insulin invivo on rat parotidgland. Am J Physiol, Bethesda, v. 245, n. 3, p. G431-G437, 1983.

ANDERSON, L. C. Parotid gland function in streptozotocin-diabetic rats.

J Dent Res, Chicago, v. 66, n. 2, p. 425-429, Feb. 1987.

ANDERSON, L. C. Insulin-stimulated protein-synthesis in submandibular acinarcells - interactions with adrenergic and cholinergic agonists. Horm Metab Res, Stutgart, v. 20, n. 1, p. 20-23, Jan. 1988.

ANDERSON, L.C.; BEVAN, C.A. Effects of streptozotocin diabetes on amylase release and camp accumulation in rat parotid acinar-cells. Arch Oral Biol, New York, v. 37, n. 5, p. 331-336, May, 1992.

ANDERSON, L.C.; GARRETT, J.R. The effects of streptozotocin-induced diabetes on norepinephrine and cholinergic enzyme-activities in rat parotid and submandibular glands. Arch Oral Biol, New York, v. 39, n. 2, p. 91-97, 1994.

ANDERSON, L. C.; GARRETT, J. R.; SULEIMAN, A.H.; PROCTOR, G. B.; CHAN, K. M.; HARTLEY, R. In vivo secretory responses of submandibular 
glands in streptozotocin-diabetic rats to sympathetic and parasympathetic nerve stimulation. Cell Tissue Res, Berlin, v. 274, n. 3, p. 559-566, Dec. 1993.

ANDERSON, J. W.; HERMAN, R. H.; TYRRELL, J. B.; COHN, R. M.

Hexokinase: a compartmented enzyme. Am J Clin Nutr, Philadelphia, v. 24, n. 6, p. 642-650, Jun 1971.

ANDERSON, L.C.; JOHNSON, D.A. Effects of alloxan diabetes on rat parotidgland and saliva. Comp Biochem Phys, Oxford, v. B 70, n. 4, p. 725-730, 1981.

ANDERSON, L.C.; SHAPIRO BL. Effect of alloxan diabetes and insulin invivo on peroxidase-activity in the rat sub-mandibular gland. Arch Oral Biol, New York, v. 24, n. 5, p. 343-345, May. 1979.

ANDERSON, L.C.; SHAPIRO, B.L. The effect of alloxan diabetes and insulin on the rate of protein-synthesis in the rat sub-mandibular gland. Horm Metab Res, Stutgart, v. 12, n. 2, p. 47-51, 1980.

ANREP, G. V.; CANNAN, R. K. The metabolism of the salivary glands. II. The blood sugar metabolism of the submaxilary gland. J Physiol, London, v. 56, p. 248-58, 1922.

ANREP, G. V.; CANNAN, R. K. The metabolism of the salivary glands. III. The blood sugar metabolism of the submaxilary gland. J Physiol, London, v. 57, p. 16, 1923.

\footnotetext{
* De acordo com NBR-6023 da Associação Brasileira de Normas Técnicas, 1989. Abreviatura de periódicos segundo "Index to Dental Literature".
} 
BANOCZY, J.; ALBRECHT, M.; RIGO, O.; EMBER, G.; RITLOP. B. Salivary secretion rate, ph, lactobacilli and yeast counts in diabetic women. Acta Diabetol Lat, Buenos Aires, v. 24, n. 3, p. 223-228, 1987.

BESSMAN, S. P.; GOTS, R. E. The hexokinase acceptor of insulin action hormonal control of functional compartmentation. Life Sci, Oxford, v. 16, n. 8, p. 1215-1225, Apr. 1975.

BROCK, N.; DRUCKEY, H.;LOCH, W. Die bedentung verschiedener aubstrate fur den stoffwechsie der gewebe. Biochem Z, Berlin, v. 313, p. 300-316, 1942. Apud: MARTIN, K. Metabolism of salivary glands. In code, CF ed. Handbook of Physiology. Alimentary canal II. Am Physiol Soc, Washington, v. 2, p. 581-593, 1967.

CHAMP, P. C.; HARVEY, R. A. Lippincotts Illustrated Reviews: Biochemistry $2^{\text {nd }}$ edition. Philadelphia: Lippincotts-Haven, 1994, 443p.

CHAVEZ, E. M.; TAYLOR, G.W.; BORRELL, L. N.; SHIP, J. A. Salivary function and glycemic control in older persons with diabetes. Oral Surg Oral Med Oral Pathol Oral Radiol Endod, St. Louis, v. 89, n. 3, p. 305-311, Mar. 2000.

CHENZION, M.; BASSUKEVITZ, Y.; BEITNER, R. Sequence of insulin effects on cytoskeletal and cytosolic phosphofructokinase, mitochondrial hexokinase, glucose 1,6-bisphosphate and fructose 2,6-bisphosphate levels, and the antagonistic action of calmodulin inhibitors, in diaphragm muscle. Int J Biochem, Bristol, v. 24, n. 10, p. 1661-1667, Oct. 1992. 
CHERRYPEPPERS, G.; SORKIN, J.; ANDRES, R.; BAUM, B. J.; SHIP, J. A. Salivary-gland function and glucose metabolic status. J Gerontol , Washington, v. 47, n. 4, p. M130-M134, 1992.

COLOSIA, A.D.; MARKER, A.J.; LANGE, A.J.; EL-MAGHRABI, M. R.; GRANNER, D. K.; TAULER, A.; PILKIS, J.; PILKIS, S. J. Induction of rat-liver 6phosphofructo-2-kinase fructose-2,6-bisphosphatase messenger-rna by refeeding and insulin. J Biol Chem , Baltimore, v. 263, n. 35, p. 18669-18677, Dec. 1988.

CONNER, S.; IRANPOUR, B.; MILLS, J. Alteration in parotid salivary flow in diabetes mellitus. Oral Surg Oral Med Oral Pathol Oral Radiol Endod, St. Louis, v. 30, n. 1, p. 55, Jan. 1970.

DEUTCH, W,; RAPPER, H. S. Respiration and functional activity. J Physiol, London, v. 87, p. 275-236, 1936.

DEUTCH, W,; RAPPER, H. S. The respiration and metabolism of submaxillary gland tissue of the cat. J Physiol, London, v. 92, p. 439-458, 1938.

DODDS, M. W. J.; DODDS, A. P. Effects of glycemic control on saliva flow rates and protein composition in non-insulin-dependent diabetes mellitus. Oral Surg Oral Med Oral Pathol Oral Radiol Endod, St. Louis, v. 83, n. 4, p. 465-470, Apr. 1997.

ENGLISH.J. A. Enzymatic activity of radiated and normal salivary gland tissues. Am J Physiol, Washington, v. 183, p. 463-474, 1955. 
FEINSTEIN, H.; SVCHRAMM, M. Energy production in rat parotid gland. Relation to enzime secretion and effects of calcium. Eur J Biochem, Berlin, v. 13, p. 158163, 1970.

FELL, D, A. Signal trandsduction and the control of expression of enzyme activity. Advan Enzyme Regul, Oxford, v. 40, p. 35-46, 2000.

FRANK, S. K.; FROMM, H. J. Effect of streptozotocin-induced diabetes on the turnover of hexokinase II in the rat. Biochem Biophys Res Commun, New York, v. 106, n. 2, p. 379-384, May. 1982.

FRANK, S. K.; FROMM, H. J. Effect of streptozotocin-induced diabetes and insulin treatment on the degradation of hexokinase II in the skeletal muscle of the rat. Biochem Biophys Res Commun, New York, v. 138, n. 1, p. 374-380, Jul. 1986.

FUKUSHIMA, E.; SUGIYA, H. Purification and characterization of phosphofructokinase in bovine parotid gland. Int J Biochem, Bristol, v. 24, n. 8, p. 1307-1314, Aug. 1992.

GOLDMAN, J.; ROSALES, F; VILLAVICENCIO, M.; GUERRA, R. Patway of glucose metabolism in rat submaxilary gland. Biochem Biophys Acta, Amsterdan, v. 82, p. 303-312, 1964.

GROSSBARD, L.; SCHIMKE, R.T. Multiple hexokinases of rat tissues. Purification and comparison of soluble forms. J Biol Chem, Baltimore, v. 241, n. 15, p. 3546-3560, Aug. 1966. 
GROSSBARD, L.; WEKSLER, M.; SCHIMKE, R. T. Electrophoretic properties and tissue distribution of multiple forms of hexokinase in various mammalian species. Biochem Biophys Res Commun, New York, v. 24, n. 1, p. 32-38, Jul. 1966.

HARRISON, R.; BOWEN, W. H. Flow rate and organic constituents of whole saliva in insulin-dependent diabetic children and adolescents. Pediatr Dent, Chicago, v. 9, n. 4, p. 287-291, Dec. 1987.

HERS, H.G.; HUE, L,; VANSCHAFTINGEN, E. Fructose 2,6-bisphosphate. Trends Biochem Sci, Amsterdan, v. 7, n. 9, p. 329-321, Sep. 1982.

HOTTA, K.; KWAJIMA, M.; ONO, A.;NAKAJIMA, H.; SHINGU, R.; MIYAGAWA, J.; NAMBA, M.; HANAFUSA, T.; NOGUCHI, T.;KONO, N. MATSUZAWA, Y. Disoedered expression of hepatic glycolytic and gluconeogenesis enzymes in Otsuka Long-Evans Tokushima fatty rats with spontaneous long-term hyperglycemia. Bioch et Biophys Acta, Amsterdan, v. 1289, p. 145-149, 1996.

KATZEN H. M. The effect of diabetes and insulin in vivo and in vitro on a low $\mathrm{Km}$, form of hexokinase from various rat tissues. Biochem Biophys Res Commun, New York, v. 24, n. 4, p. 531-536, Aug. 1966.

KATZEN, H. M.; SCHIMKE, R. T. Multiple forms of hexokinase in the rat: tissue distribution, age dependency, and properties. Proc Natl Acad Sci U S A, Allahabad, v. 54, n. 4, p. 1218-1225, Oct. 1965. 
KIM, S. K.; CUZZORT, L. M.; MCKEAN, R. K. ; ALLEN, E. D. Effects of diabetes and insulin on alpha-amylase messenger-rna levels in rat parotid-glands. J Dent Res, Chicago, v. 69, n. 8, p. 1500-1504, Aug. 1990.

KIMURA, I.; MIYAMOTO, H.; CHEN, F. J.; KIMURA, M. The streptozocin-diabetic state depresses saliva secretion stimulated by pilocarpine and noradrenaline in mice. Biol Pharm Bull, Tokyo, v.19, n. 3, p. 384-387, Mar. 1996.

KJELLMAN, O. Secretion rate and buffering action of whole mixed saliva in subjects with insulin-treated diabetes mellitus. Odontol Revy, Lund, v. 21, n. 2, p. 159-168, 1970.

KNULL, H. R.; LAMB, S. M. Hexokinase in salivary gland. Comp Biochem Physiol B, Oxford, vol 65, n. 6, p. 743-746, Jun. 1980.

KNULL, H. R.; TAYLOR, W. F.; WELLS, W. W. Effects of energy metabolism on in vivo distribution of hexokinase in brain. J Biol Chem, Baltimore, v. 248, n. 15, p. 5414-5417, Aug. 1973.

KODAIRA, T.; YOKOYAMA, N. Distribution and regulation of mitochondrial hexokinase in rat submandibular gland. Comp Biochem Physiol B, Oxford, v. 74, n. 2, p. 235-241, Feb. 1983.

KOVAL, J. A.; DEFRONZO, R. A.; O’DOHERTY, R. M.; PRINTZ, R.; ARDEHALL, H.; GRANNER, D. K.; MANDARINO, L. J. Regulation of hexokinase Il activity and expression in human muscle by moderate exercice. Am J Physiol, Bethesda, v. 274, 2 Pt 1, p. E304-308, Feb. 1998. 
LAMEY, P. J.; FISHER, B. M.; FRIER, B. M. The effects of diabetes and autonomic neuropathy on parotid salivary flow in man. Diabetic Med, W. Sussex, v. 3, n. 6, p. 537-540, Nov/Dec. 1986.

LAURENCE, J. C. JR. Signal transduction and protein phosphorylation in the regulation of cellular metabolism by insulin. Annu Rev Physiol, Palo Alto, v. 54, p. 177-193, 1992.

LEHNINGER, A. L.; NELSON, D. L.; COX, M. M. Principles of Biochemistry. New York: Worth Publishers, 1997, 1013p.

LITTLE, J. W. Recent advances in diabetes mellitus of interest of dentistry. Spec Care Dent, Chicago, v. 20, n. 2, p. 46-52, Fev. 2000.

LIU, F. T. Y.; LIN, H. S. Role of insulin in body growth and growth of salivary and endocrine glands in rats. J Dent Res, Chicago. v. 48, n. 4, p. 559-567, 1969a.

LIU, F. T. Y.; LIN, H. S. Relationship between insulin and growth hormone in growth and development of rat submandibular glands. P Soc Exp Biol Med, New York, v. 131, n. 1, p. 175-179, $1969 b$.

LOWRY, O. H.; ROSENBROUGH, N. S.; FARR, A. L. RANDALL, R. J. Protein measurement with the folin phenol reagent. J Biol Chem, Baltimore, v. 193, p. 265-75, 1951.

LUTHER, M. A.; LEE, J.C. The role of phosphorylation in the interaction of rabbit muscle phosphofructokinase with f-actin. J Biol Chem, Baltimore, v. 261, n. 4, p. 1753-1759, Apr. 1986. 
MADESEN, K. L.; ARIANO, D.; FEDORAK, R. N. Vanadate treatment rapidly improves glucose transport and activates 6-phosphofructose-1-kinase in diabetic rat intestine. Diabetologia, Heidelberg, v. 38, p. 403-412, 1995.

MARDER, M.Z.; ABELSON, D. C. ; MANDEL, I. D. Salivary alterations in diabetes-mellitus. J Periodontol, Birminghan, v. 46, n. 9, p. 567-569, Sep. 1975. MARYNISSEN, G.; SENER,A.; MALAISSE, W. J. Activity and kinetics of liver 6phosphofructokinase in normal and diabetic rats. Diab Res, Edinburg, v. 12, n. 3, p. 117-122, Nov. 1989.

MASI, I.; POCCHIARI, F.; SZYMCZYK, T. Metabolismo del glucosio nella ghiandola sottomascellare di ratto in vitro. Effecto dell insulina. Ann Ist Super, Sanita, v. 2, p. 287-295, 1966.

MEURMAN, J. H.; COLLIN, H. L.; NISKANEN, L.; TOYRY, J.; ALAKUIJALA, P.; KEINANEN, S.; UUSITUPA, M. Saliva in non-insulin-dependent diabetic patients and control subjects: The role of the autonomic nervous system. Oral Surg Oral Med Oral Pathol Oral Radiol Endod, St. Louis, v. 86, n. 1, p. 69-76, Jul. 1998. MORENO-AURIOLES, V. R.; ROCIO, M.; CONDE, M. BUSTOS, R. SOBRINO, F. Streptozotocin-induced diabetes increases fructose 2,6-bisfosfate levels and glucose metabolism in thymus lymphocytes. Life Sci, Amsterdan, v. 58, n. 6, p. 477-484, 1996.

MURAI, S.; SAITO, H.; MASUDA, Y.; et al. Effects of short-term (2 weeks) streptozotocin-induced diabetes on acetylcholine and noradrenaline in the salivary glands and secretory responses to cholinergic and adrenergic 
sialogogues in mice. Arch Oral Biol, New York, v. 41, n. 7, p. 673-677, Jul. 1996.

MURAKAMI, H. Changes in activities of several enzymes for carbohydrate metabolism in the rat submaxillary gland in response to experimental diabetes and insulin treatment. J Nihon Univ Sch Dent, Tokyo, v. 16, n. 4, p. 91-94, Dec. 1974.

NELSON, N. Photometric adaptation of the Somogyi method for the determination of glucose. J Biol Chem, Baltimore, v. 153, p. 375-380, 1944.

NEWRICK, P. G.; BOWMAN, C.; GREEN, D.; O'BRIEN, I. A.; PORTER, S. R.; SCULLY, C.; CORRALL, R. J. Parotid salivary secretion in diabetic autonomic neuropathy. HNO, Hagerstown, v. 5, n. 1, p. 35-37, Mar. 1991.

NICOLAU, J.; DESOUZA, D. N.; MARTINS, H.R. Pilocarpine-induced increases in the activity of 6-phosphofructo-2-kinase and the fructose-2,6-bisphosphate content of rat salivary-glands. Arch Oral Biol, New York, v. 37, n. 6, p. 483-487, Jun. 1992.

NICOLAU, J.; LANSAC, M. C.; ROSA, R.; PEDROSO, F. I.; LEAL, A. Activities of some glycolitic enzymes in the major salivary glands of soome laboratory animals. Comp Biochem Physiol, New York, v. 46A, p. 399-402, 1974.

NICOLAU, J.; NUNEZ-BURGOS, G. Phosphofructokinase-1 in the nuclear and cytoplasmic fraction of the submandibular salivary glands from isoproterenoltreated rats: Km and isoenzimes. Med Sci Res, Lancaster, v. 19, p. 381-383, 1991. 
NICOLAU, J.; SASSAKI, K. T. Metabolism of carbohydrate in the major salivary glands of mice. Arch Oral Biol, Oxford, v. 21, n. 11, p. 659-661, Jun. 1976.

NISHIMURA, H.; KUZUYA, H.; OKAMOTO, M.; YAMADA, K.; KOSAKI, A.; KAKEHI, T.; INOUE, G.; KONO, S.; IMURA, H. Postreceptor defect in insulin action in streptozotocin-induced diabetic rats. Am J Physiol, Bethesda, v. 256, n. 5, p. E624-E630, May. 1989.

NOTKINS, A. L. Causes of diabetes. Sci Am, New York, v. 241, n. 5, p. 62-73, May. 1979

OSAWA, H.; SYTHERLAND, C.; ROBEY, R. B.; PRINTZ, R. L.; GRANNER, D. $\mathrm{K}$. Analysis of the signaling pathway involved in the regulation of hexokinase II gene transcription gy insulin. J Biol Chem, Bethesda, v. 271, n. 28, p. 1669016694, Jul. 1996.

PEDROSO, F. I.; LEAL, A.; ROSA, R.; NICOLAU, J. Metabolism in vitro of the submaxilary salivary gland from rats subjected to various nutrional conditions. Arch Oral Biol, Oxford, v. 21, n. 9, p. 499-502, Sep. 1976.

PILKIS, S. J.; EL-MAGHRABI, M. R.; MCGRANE, M.; PILKIS, J.; FOX, E.; CLAUS, T. H. Fructose 2,6-bisphosphate - a mediator of hormone action at the fructose 6-phosphate fructose-1,6-bisphosphate substrate cycle. Mol Cell Endocrinol, Amsterdan, v. 25, n. 3, p. 245-266, 1982.

SANTTI, R. S.; VILLEE, C. A. Hormonal control of hexokinase in male sex accessory glands. Endocrinology, Springfield, v. 89, n. 5, p. 1162-1170, Nov. 1971. 
SCACCHI, G. E.; WALD, M. R.; TURYN, D.; DELLACHA, J. M. Effect of proteolytic enzymes on masked insulin receptors in rat submaxillary gland microsomes. Horm Metab Res, Stutgart, v. 20, n. 1, p. 15-19, Jan. 1988.

SHARON, A.; BEN-ARYEH, H.; ITZHAK, B.; YORAM, K.; SZARGEL, R.;

GUTMAN, D. Salivary composition in diabetic patients. J Oral Med, New York, v. 40, n. 1, p. 23-26, Jan/Mar. 1985.

SOCHOR, M.; BAQUER, N. Z.; HOTHERSALL, J. S.; McLEAN, P. Effect of experimental diabetes on the activity of hexoqinase isoenzimes in tissues of the rat. Biochem Int, New York, v. 22, n. 3, p. 467-474, Nov. 1990.

SRIVASTAVA, L. K.; BAQUER, N. Z. Changes in phosphofructokinase and pyruvate kinase in rat brein regions during alloxan-induced diabetes. Enzyme, Basel, v. 32, p. 84-88, 1984.

STRECKFUS, C. F.; MARCUS, S.; WELSH, S.; BROWN, R. S.; CHERRYPEPPERS, G.; BROWN, R. H. Parotid function and composition of parotid-saliva among elderly edentulous african-american diabetics. J Oral Pathol Med, Copenhagen, v. 23, n. 6, p. 277-279, Jun. 1994.

TROMBLAD, B. R. C. Oxygen comsumption of the normal and denervated submaxillary gland in vitro. Acta Physiol Scand, Copenhagen, v. 40, p. 130-145.

TROMBLAD, B. R. C. Oxygen comsumption of the normal and denervated submaxillary gland of the cat. J Physiol, London, v. 145, p. 551-561. 
SZCZEPANSKI, A.; MEDNIEKS, M. I.; HAND, A. R. Expression and distribution of parotid secretory proteins in experimental diabetes. Eur J Morphol, Lisse, vol 36, Suppl , p. 240-246, Aug. 1998.

TENOVUO, J. Human Saliva: Chemistry and Microbiology. Vol I. Boca Raton: CRC Press, 1989, 205p.

TENOVUO, J.; LEHTONEN, O. P.; VIIKARI, J.; LARJAVA, H.; VILJA, P.; TUOHIMAA, P. Immunoglobulins and innate antimicrobial factors in whole saliva of patients with insulin-dependent diabetes-mellitus. J Dent Res, Chicago, v. 65, n. 1, p. 62-66, Jan. 1986a.

TENOVUO, J.; ALANEN, P.; LARJAVA, H.; VIIKARI, J.; LEHTONEN, O. P. Oral health of patients with insulin-dependent diabetes mellitus. Scand J Dent Res, Copenhagen, v. 94,n. 4, p. 338-346, Aug 1986b.

TERROUX, K. G.; SEKEL, J. P. BURGEN, S. V. Oxygon consumption and blood flow in the submaxillary gland of the dog. Can J Biochem Physiol, Montreal, v. 37, p. 5-15, 1959.

THORSTENSSON, H.; FALK, H.; HUGOSON, A.; OLSSON, J. Some salivary factors in insulin-dependent diabetics. Acta Odontol Scand, Stockholm, v. 47, n. 3, p. 175-183, 1989.

UYEDA, K.; MIYATAKE, A.; LUBY, L.J.; RICHARDS, E. G. Isolation and characterization of muscle phosphofructokinases with varying degrees of phosphorylation. J Biol Chem, Baltimore, v. 253, n. 22, p. 8319-8327, 1978.

VANSCHAFTINGEN, E.; HERS, H.G. Synthesis of a stimulator of phosphofructokinase, most likely fructose 2,6-bis-phosphate, from phosphoric- 
acid and fructose 6-phosphoric acid. Biochem Bioph Res Co, New York, v. 96, n. 4 , p. 1524-1531, 1980.

VIITANEN, P.V.; GEIGER, P.J.; ERICKSON-VIITANEN, S.; BESSMAN, S. P. Evidence for functional hexokinase compartmentation in rat skeletal-muscle mitochondria. J Biol Chem, Baltimore, v. 259, n. 15, p. 9679-9686, 1984. WANG, P.L.; PURUSHOTHAM, K.R.; HUMPHREYSBEHER, M.G. Effect of chronic insulin administration on mouse parotid and submandibular-gland function. P Soc Exp Biol Med, New York, v. 205, n. 4, p. 353-361, Apr. 1994. WHITE, M.F.; KAHN, C.R. The insulin signaling system. J Biol Chem, Baltimore, v. 269, n. 1, p. 1-4, Jan. 1994. 


\section{SUMMARY}

\section{INFLUENCE OF DIABETES ON THE ACTIVITY AND DISTRUITION OF THE ENZIMES HEXOKINASE AND PHOSPHOFRUCTOKINASE OF THE RAT PAROTID AND SUBMANDIBULAR GLAND}

We have studied in the present investigation a possible influence of the diabetic state of the rats on the activity of two important enzymes of the glycolitic pathway, namely, the HK and PFK-1 of the submandibular and parotid gland. The diabetic state was induced by an injection of streptozotocin $(60 \mathrm{mg} / \mathrm{Kg}$ body weight) dissolved in $0,1 \mathrm{M}$ citrate buffer $\mathrm{pH} 4,5$ in rats overnight fasted. Forty-eight hours after the injection, blood was collected and the glucose determined. Only those animals presenting a blood glucose equal or above $350 \mathrm{mg}$ glucose $/ 100 \mathrm{ml}$ blood we used in this experiment. The animals were sacrificed by cranial traumatism, thirty days after the induction of the diabetes, the submandibular and parotid glands were removed and analyzed for activity and distribution of the enzymes HK and PFK-1. The activity of the enzyme HK was determined in the cytosol (soluble fraction) and bound to mitochondria (solubilized fraction). The activity of the enzyme PFK-1 was determined in the cytosol (soluble fraction) 
and bounded to cytoscheletal (bound fraction)at two pHs, $\mathrm{pH} \mathrm{6,9} \mathrm{that}$ respond to allosteric regulation and $\mathrm{pH} 8,2$ in which it show maximum activity. In the parotid gland it was observed an increase in the HK activity in both fractions, soluble and bond to mitochondria, of about $33 \%$ and $85 \%$ respectively. It was not possible to observe alterations in the isoenzymes profile. The activity of PFK-1 in the parotid gland showed no variation either considering the soluble fraction on the bound form, at both $\mathrm{pHs}$ in which it was determined. In the submandibular gland, it was verified a reduction of the bound HK of about $74 \%$, but no variation in the soluble form. Concerning the isoenzymes, it was observed the disappearance of an isoenzyme in both fraction. On the other hand, we observed an increase in the activity of PFK-1 of the soluble fraction of about $50 \%$, when determined at $\mathrm{pH} 6,9, \mathrm{pH}$ in which it respond to allosteric control, and about $84 \%$ when determined at $\mathrm{pH} 8,2$. Contrary to what it was expected, the content of Fru-2,6- $\mathrm{P}_{2}$ were reduced in the submandibular gland of diabetic rats. 


\section{AUTORIZAÇÃO}

Autorizo a reprodução e/ou divulgação total ou parcial da presente obra, por qualquer meio convencional ou eletrônico, desde que citada a fonte e comunicada, ao autor, a referência bibliográfica em que consta a citação.

\section{Fernando Neves Nogueira}

\section{Assinatura}

Instituição: Faculdade de Odontologia da USP

Local e data: São Paulo, 20 de Julho de 2001.

Endereço: Av. Professor Lineu Prestes, 2227

E-mail: fnn@fo.usp.br 